\title{
Biocatalytic Synthesis of Flavonoid Esters by Lipases and Their Biological Benefits
}

\author{
Authors \\ Maria Elisa M. B. de Araújo ${ }^{1}$, Yollanda E. M. Franco ${ }^{1}$, \\ Marcia C. F. Messias ${ }^{1}$, Giovanna B. Longato ${ }^{1}$, João A. Pamphile², \\ Patricia de O. Carvalho ${ }^{1}$ \\ Affiliations \\ 1 Laboratory of Multidisciplinary Research, São Francisco University, \\ USF, Bragança Paulista, SP, Brazil \\ 2 Department of Biotechnology, Genetics and Cell Biology, State \\ University of Maringá, UEM, Maringá, PR, Brazil \\ Key words \\ flavonoids, lipase, acylation, biocatalysis \\ received Sept. 28, 2016 \\ revised Sept. 28, 2016 \\ accepted October 6, 2016 \\ Bibliography \\ DOI http://dx.doi.org/10.1055/s-0042-118883 \\ Published online December 5, 2016 | Planta Med 2017; 83: 7-22 \\ (c) Georg Thieme Verlag KG Stuttgart · New York I ISSN 0032-0943 \\ Correspondence \\ Maria Elisa Melo Branco de Araújo \\ Laboratory of Multidisciplinary Research, São Francisco University, USF \\ São Francisco de Assis Avenue, 218, 12916-900, Bragança Paulista, SP, \\ Brazil \\ Tel.: + 551124548298 , Fax: + 551124548298 \\ melisa.bio@gmail.com
}

\begin{abstract}
Several studies have described important biological activities of flavonoids such as coronary heart disease prevention, hepatoprotective, anti-inflammatory and anticancer activities, enzyme inhibition activity, and antibacterial, antifungal, and antiviral activities. Flavonoids show promising activity as natural plant-based antioxidants due to their antioxidant and free radical scavenging properties. However, their primary applications as antioxidants in the pharmaceutical, cosmetic, and food industries are limited because of their moderately hydrophilic nature. Enzymatic acylation of natural polyphenols with fatty acids or other acyl donors has been suggested for improving the lipophilic nature of the glycosylated flavonoids. This approach increases flavonoid solubility and stability in lipophilic systems. Acylation of flavonoids with different acyl donors may also introduce beneficial properties to the molecule, such as penetration through the cell membrane and improved antioxidant, antimicrobial, anti-inflammatory, antiproliferative, cytogenetic, and enzyme inhibition activities. Chemical methods for the synthesis of flavonoid esters lead to the formation of side products and the simultaneous decomposition of the flavonoids due to harsh reaction conditions. In contrast, biocatalytic acylation of flavonoids by lipases offers advantages associated to the wide availability of these enzymes, their low cost, chemo-, regio-, and enantioselectivity, mild condition processing and non-requirement of cofactors. This article is focused on the recent development of lipase-catalyzed synthesis of flavonoid esters and the impact of the acylation reaction on their biological activities.
\end{abstract}

\section{Introduction}

Flavonoids form a class of well-known natural products that are present in most of the plant families. These compounds are of great industrial interest due to their potentially beneficial bioactivities and, to date, more than 8000 different flavonoids have been isolated from their natural sources. The structural variations of these flavonoids are associated with many different biological and pharmacological activities such as antioxidative activity, free radical scavenging capacity, coronary heart disease prevention, hepatoprotective, anti-inflammatory and anticancer activities, enzyme inhibition activity, and antibacterial, antifungal, and antiviral activities [1].

Natural flavonoids have therefore been subjected to many structural modifications in order to improve their activity and physicochemical properties. As part of the approach to generating more active flavonoid derivatives and increasing the solubility and stability of glycosylated flavonoids in lipophilic systems, the addition of an acyl group to the flavonoid structure results in se- lectively acylated flavonoids. Acylation of flavonoids using different aliphatic or aromatic acids shows promising industrial applications. Special attention has been paid to the production of flavonoid fatty acid esters with potential biological activities [2-14].

Improvement of the hydrophilic nature and stability of flavonoids can be accomplished by chemical, enzymatic, or chemoenzymatic structural modification [15]. Chemical methods raise concern regarding adverse environmental impacts, safety, and waste. In addition, when a chemical method is used, many protection/deprotection steps are required to obtain selective functionalization because of the numerous reactive hydroxyl groups in flavonoid structures. On the contrary, biocatalytic methods can be used in both simple and complex transformations without the tedious blocking and deblocking steps that are common in enantioand regioselective organic synthesis. Such high selectivity also favors efficient reactions with few by-products $[16,17]$. Moreover, the advantage of biocatalysis lies in its ability to produce enantiomer specific products and operate at near-neutral $\mathrm{pH}$, ambient temperatures, and atmospheric pressures. For chemoenzymatic flavonoid acylation in vitro, a wide range of hydrolytic en- 
zymes has been used, including lipases, transferases, isomerases, esterases, and proteases. Lipases have been the most frequently used enzyme in catalyzing flavonoid acylation [18-20]. This paper summarizes possibilities for the enzymatic acylation of flavonoids, with particular emphasis on the biological activities of the acylated molecules.

\section{Synthesis of Flavonoid Esters Using Lipases}

Most flavonoids from natural sources occur in their glycosylated form, which limits their applications in some fields due to their low solubility in lipophilic systems [19].

The lipophilicity of flavonoids and their ability to interact with the cell membrane are important factors that influence their pharmacological activity. Many flavonoids present a number of hydroxyl groups that provide some polarity and weak acidic properties to the molecules [21]. The inverse correlation between the number of hydroxyl groups and the lipophilicity of flavonoids has been demonstrated experimentally [22]. The bioactivities of flavonoids and their metabolites depend on their chemical structure, which may show substitutions such as hydrogenations, methylations, malonylations, sulphatations, and glycosylations.

A solution for increasing the hydrophobic nature (lipophilization) of flavonoids is to convert their hydroxyl functions into esters through an acylation reaction with aliphatic or aromatic acid derivatives. The acylation of flavonoids may be performed by two methods: chemically or enzymatically. The enzymatic method is notably more selective [10] and occurs in mild reaction conditions, avoiding several steps required by the classical chemical methods [23]. Hydrolytic enzymes (lipases, esterases, and proteases) have become recognized as effective biocatalysts due to their wide availability, low cost, and lack of need for cofactors $[24,25]$. Among all the hydrolases, lipases are the most efficient and well-studied biocatalysts for acylation reactions of flavonoids.

Lipases or triacylglycerol hydrolases (EC 3.1.1.3) are carboxylesterases that belong to the class of serine hydrolases. Under natural conditions, lipases catalyze the hydrolysis of ester bonds at the hydrophilic-hydrophobic interface. Under certain conditions, especially in the absence of water, lipases are able to reverse the reaction, which leads to esterification, with the formation of glycerides from fatty acids and glycerol [26]. This synthesis activity of lipases has been successfully employed in the production of flavonoid esters in order to improve their physicochemical and biological properties.

The specificity of lipases is also an important tool for the production of specific compounds. Lipases may be: 1) chemoselective, 2) regioselective, or 3) stereoselective. Regarding the selectivity of lipases towards different chain-length acyl groups, these enzymes are often able to hydrolyze long-chain TAGs. However, lipase B from Candida antarctica, one of the most widely applied lipases in food industries and in organic synthesis, does not have this property [27].

Enzymatic acylation of flavonoids may be performed by direct esterification or transesterification [18], as shown in • Fig. $\mathbf{1 .}$

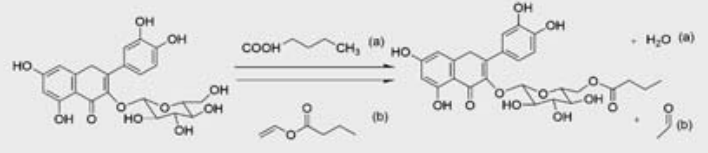

- Fig. 1 Enzymatic acylation of flavonoids: a esterification, b transesterification [18].

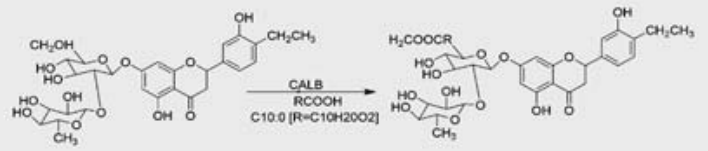

- Fig. 2 Enzymatic acylation of hesperidin with decanoic acid catalyzed by CALB [32].

Several types of lipase are capable of catalyzing the acylation of flavonoid glycosides, while the aglycone forms are acylated only by lipase from Pseudomonas cepacia [18].

C. antarctica lipase B (CALB) is an excellent biocatalyst with high enantioselectivity and regioselectivity. Its frequent use in organic synthesis is due to its ability to accept various substrates, its tolerance to nonaqueous media, and its resistance to thermal inactivation [28-30]. CALB belongs to the superfamily of $\alpha / \beta$ hydrolases. It has 317 amino acid residues and a conserved catalytic triad of amino acids: serine, histidine, and aspartic acid (Ser105His224-Asp187) [31].

Reports have shown that CALB is capable of acylating flavonoid glycosides and has a little activity for tertiary alcohols and aglycone polyphenols but no detectable activity for flavonoid aglycones. To date, only one study reporting the acylation of flavonoid aglycones by CALB is available in the literature [23].

- Fig. 2 shows the acylation of a citrus flavanone, hesperidin, with decanoic acid, catalyzed by CALB. Our study research group recently reported the optimization of this process by Response Surface Methodology. The conversion rate of hesperidin to its ester (hesperidin decanoate) in the optimized conditions was $55.0 \%$ [32].

Some authors have investigated the regioselectivity of CALB in the acylation of rutin and isoquercetin by molecular modeling [33]. According to their reports, the aglycon portion of flavonoids is stabilized at the entrance of the enzyme-binding site by hydrogen bonds and hydrophobic interactions, locating its glycoside residue near the center of the site. Only the primary 6" hydroxyl group of the isoquercetin glucose and the secondary 4" hydroxyl group of the rutin rhamnose are acylated, as they stabilize close to the catalytic sites. The potential sites for lipase-catalyzed acylation are shown in $>$ Fig. 3 [18].

Kinetic analyses have shown that the rutin acylation reaction with lauric acid in acetone, catalyzed by CALB, follows a pingpong, bi-bi mechanism with no apparent inhibition by the sub- 


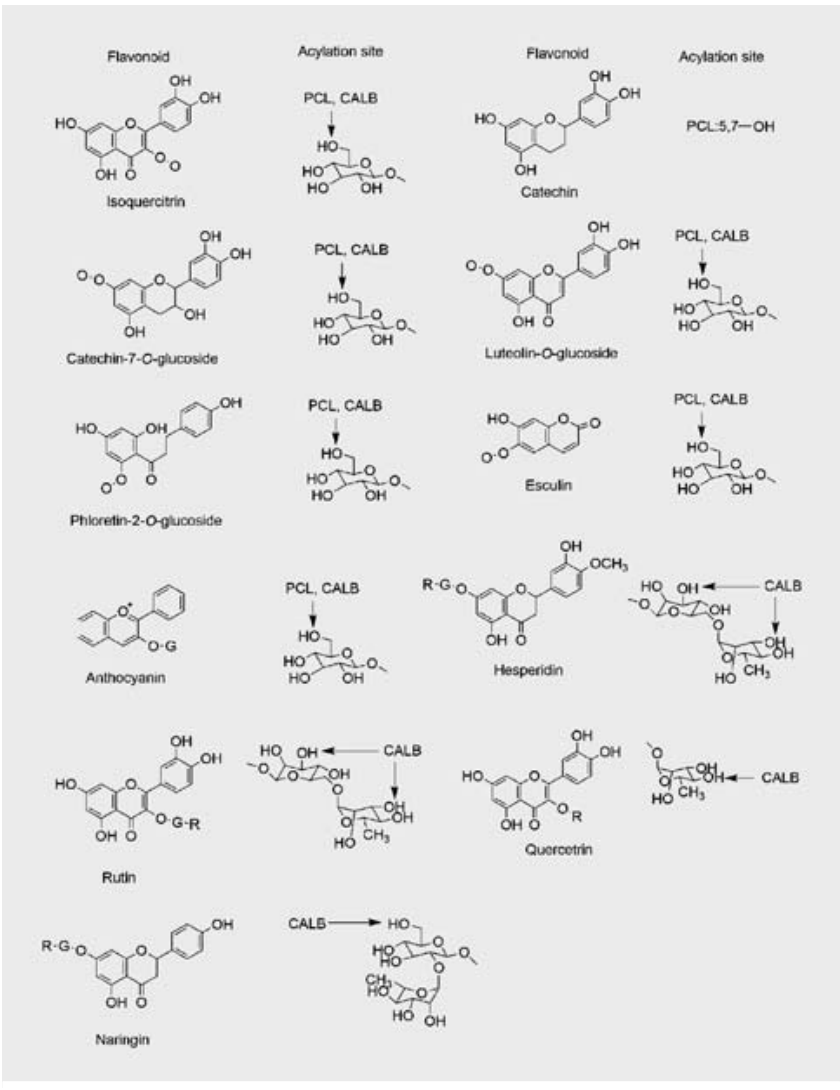

- Fig. 3 Potential esterification sites for lipase-catalyzed acylation reactions [18].

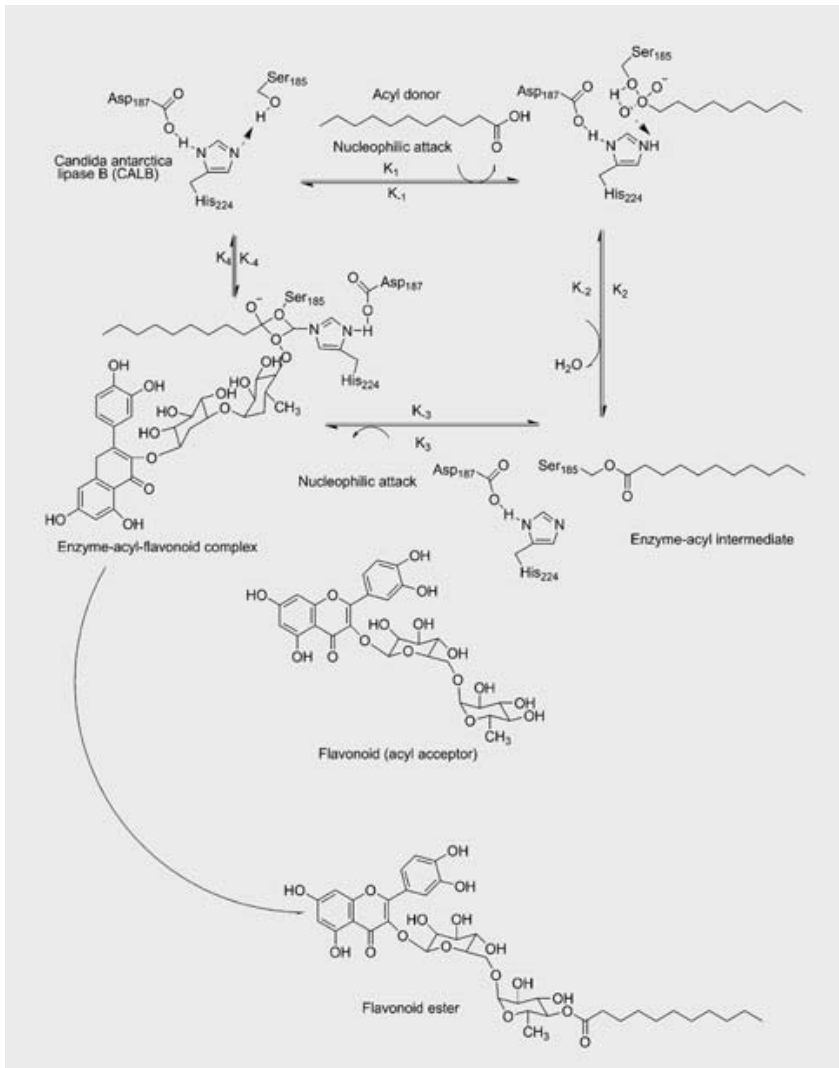

- Fig. 4 Mechanism of acylation of glycosylated flavonoids catalyzed by C. antarctica lipase B (CALB) [34]. strates [34]. The esterification reaction energy of activation ( $\left.E_{a t}\right)$ was calculated as $\sim 37 \mathrm{~kJ} \cdot \mathrm{mol}^{-1}$. The process is endothermic, with enthalpy $(\Delta \mathrm{H})$ and entropy $(\Delta \mathrm{S})$ values of about $+50 \mathrm{~kJ} \cdot \mathrm{mol}^{-1}$ and $+110 \mathrm{~kJ} \cdot \mathrm{mol}^{-1}$, respectively. Based on the free Gibbs energy value $(\Delta \mathrm{G})$, the reaction under the described conditions was predicted as not spontaneous at temperatures below $175^{\circ} \mathrm{C}$ and spontaneous at higher temperatures. The study also confirmed, through ${ }^{13} \mathrm{C}$ NMR analysis, the exact site of the esterification of rutin, as can be seen in $>$ Fig. 4 [34].

The regioselectivity and conversion rates of the enzyme-catalyzed acylation of flavonoids are influenced by several factors, such as the composition and water content of the reaction medium, the nature and chain length of the acyl donor, the acyl donor/flavonoid molar ratio, and the temperature. These factors are better described below.

\section{Factors That Influence the Flavonoid Acylation Reactions}

\section{Composition and water content of the reaction medium}

In biotransformation reactions, the composition of the reaction medium plays a determinant role. The immiscibility of substrates is presented as a particular problem [34], which makes it impor- tant to choose a reaction medium that allows for the adequate solubilization of both the glycosylated flavonoid (a polar molecule) and nonpolar acyl donor at the same time, leading to the highest possible enzyme activity.

Although the structure of CALB is highly stable in solvents, lower dielectric constants of nonpolar solvents lead to a decrease in enzyme flexibility due to interactions between organic solvent molecules and the enzyme, and to the interaction with the enzyme-bound water and its exchange on the surface [35].

At first, polar aprotic solvents, such as DMSO, dimethylformamide (DMF), tetrahydrofuran (THF), and pyridine, were investigated for the enzymatic transformation of flavonoids [36,37]. However, it was noticed that enzyme activity was deactivated in those solvents. To date, the most frequently used solvents in flavonoid acylation reactions are 2-methyl-2-butanol [7, 10, 38-42] and acetone $[7,8,14,20,41,43-48]$. These solvents present low toxicity, and their polarity permits the proper solubilization of the substrates, leading to high conversion rates [49]. Other organic solvents commonly employed are 2-methylpropan-2-ol, hexane, and acetonitrile [50]. - Table 1 summarizes some organic solvents used as media for lipase-catalyzed acylation reactions.

Room temperature ionic liquids represent an interesting "green" alternative to the use of organic solvents in biocatalysis reactions. These compounds are salts that do not crystallize at room temperature [51]. They possess physicochemical properties 
- Table 1 Organic solvents as media for flavonoid acylation reactions catalyzed by C. antarctica B (CALB) lipase.

\begin{tabular}{|c|c|c|c|}
\hline Organic solvent & Flavonoid & Acyl donor & Reference \\
\hline $\begin{array}{l}\text { Acetone, 2-methyl-2-butanol, 2-methyl- } \\
\text { 2-propanol, tetrahydrofurane, aceto- } \\
\text { nitrile }\end{array}$ & naringin & $\begin{array}{l}\text { FAs (oleic, linolenic, linoleic) and FA esters (ethyl } \\
\text { linoleate) }\end{array}$ & [7] \\
\hline tert-Butanol, acetone & naringin, chrysoeriol & FAs (decanoic, lauric, stearic) and vinyl esters & {$[8]$} \\
\hline tert-Amyl alcohol & rutin, esculin & $\begin{array}{l}\text { FAs (lauric, myristic, palmitic, stearic, adipic, } \\
\text { azelaic, dodecandioic, hexadecandioic, } \\
\text { 11-aminoundecanoic, 11-mercaptoundecanoic) }\end{array}$ & [9] \\
\hline 2-Methyl-2-butanol & $\begin{array}{l}\text { quercetin, hesperidin, rutin, } \\
\text { esculin }\end{array}$ & $\begin{array}{l}\text { saturated FAs (C6:0, C7:0, C9:0, C12:0, C14:0, } \\
\text { C16:0, C18:0, C18:1) }\end{array}$ & {$[10]$} \\
\hline Methyl benzoate, methyl salicylate & phloridzin & cinnamic acid ethyl esters & {$[12]$} \\
\hline Acetone, tert-butanol, tetrahydrofurane & naringin, rutin & FAs (8-12 C) and their esters & {$[14]$} \\
\hline $\begin{array}{l}\text { Acetone, acetonitrile, tert-amyl alcohol, } \\
\text { tert-butyl alcohol }\end{array}$ & silibin and rutin & FAs (decanoic, lauric, butyric, oleic) & {$[20]$} \\
\hline Acetonitrile & quercetin, naringenin & FA esters (vinyl acetate, vinyl butyrate) & {$[23]$} \\
\hline 2-Methyl-2-butanol & isoquercetin & $\begin{array}{l}\text { FA ethyl esters (decanoate, caprilate, caproate, } \\
\text { butyrate, laurate, stearate, palmitate, oleate) }\end{array}$ & {$[38]$} \\
\hline 2-Methyl-2-butanol & rutin & FAs (C14-C18) & [39] \\
\hline 2-Methyl-2-butanol & naringin & FAs (palmitic acid) and its methyl ester & {$[40]$} \\
\hline $\begin{array}{l}\text { Acetone, acetonitrile, 2-methyl-2- } \\
\text { butanol, 2-methyl-2-propanol }\end{array}$ & silibin & $\begin{array}{l}\text { FAs (hexanedioic, dodecanedioic, } \\
\text { hexadecanedioic) }\end{array}$ & {$[41]$} \\
\hline 2-Methyl-2-butanol & isorhamnetin-3-O-glucoside & FA esters (ethyl butyrate, ethyl laurate) & {$[42]$} \\
\hline Acetone & salicin, helicin, esculin, naringin & FA esters (vinyl butyrate) & {$[43]$} \\
\hline $\begin{array}{l}\text { Acetone, acetonitrile, tetrahydrofurane, } \\
\text { tert-butanol }\end{array}$ & naringin, prunin & FA esters (vinyl laurate) & {$[44]$} \\
\hline Acetone & rutin & FAs (palmitic, lauric) & {$[45]$} \\
\hline Acetone & naringin & Castor oil and its FAs (ricinoleic) & {$[46]$} \\
\hline Acetone & prunin & FA esters (vinyl laurate) & {$[47]$} \\
\hline Acetone & phloridzin, isoquercitrin & $\begin{array}{l}\text { FAs (oleic, stearic, linolenic, linoleic, } \\
\text { eicosapentaenoic, docosahexaenoic) }\end{array}$ & {$[48]$} \\
\hline 2-Methyl-2-propanol & $\begin{array}{l}\text { proanthocyanidin, antho- } \\
\text { cyanidin, naringin, quercetin }\end{array}$ & $\begin{array}{l}\text { FAs (palmitic, cinnamic, phenylpropionic, 2-hy- } \\
\text { droxi-, 4-hydroxi-, 3,4-dihydroxi phenylpropionic) }\end{array}$ & {$[60]$} \\
\hline tert-Amyl alcohol, acetone, tert-butanol & isoorientin, isovitexin & FAs $(\mathrm{C} 12, \mathrm{C} 14, \mathrm{C} 16)$ & {$[84]$} \\
\hline
\end{tabular}

that potentially promote esterification reactions catalyzed by lipases, such as the absence of vapor pressure and high thermal stability. Also, they have reduced toxicity when compared to organic solvents and may be easier to efficiently reuse due to the absence of vapor pressure [52]. Ionic liquids can be used in biocatalytic processes as pure solvents, as cosolvents in aqueous systems, and in biphasic systems [53]. - Fig. 5 shows some examples of cations and anions present in ionic liquids.

Ionic liquids can be synthesized to have different polarities, to be water miscible or immiscible, and to have different viscosities, and these properties can influence the stability and activity of enzymes [54]. Unlike some polar organic solvents, ionic liquids do not inactivate enzymes. This fact represents an advantage when polar substrates are used in enzyme-catalyzed reactions [55]. Water-immiscible ionic liquids, possessing a long hydrophobic alkyl chain, are less prone to stripping off the essential water from the enzyme, so they preserve high enzyme activity. Enzymes are usually active in ionic liquids containing anions of $\mathrm{BF}_{4}, \mathrm{PF}_{6}$, and $\mathrm{Tf}_{2} \mathrm{~N}[53]$.

Spectroscopy analyses of the structural and conformational dynamics of CALB in ionic liquids have shown that the stabilization of the enzyme in [emim] $\left[\mathrm{Tf}_{2} \mathrm{~N}\right]$ and [btma] $\left[\mathrm{Tf}_{2} \mathrm{~N}\right]$ was due to the maintenance of the $\alpha$-helix content and the enhancement of $\beta$ strands [56]. Intrinsic fluorescence studies showed that enzyme unfolding occurred in water and the hexane, but the structural changes associated with the incubation of the enzyme in ionic liquids were attributed to a compact and active enzyme conformation that enhanced CALB stability [56].

In a study about the acylation of salicin, helicin, esculin, and naringin in acetone and in ionic liquids ([bmim] $\mathrm{BF}_{4}$ and [bmim] $\mathrm{PF}_{6}$ ), catalyzed by $C A L B$, the authors reported that the solubility of glycosides was greater in [bmim] $\mathrm{BF}_{4}$, resulting in higher conversion rates (up to $87.0 \%$ ) and greater regioselectivity compared to other media [43]. 
The solubility of commercial rutin and esculin in 14 different ionic liquids was analyzed using COSMO-RS, and the acylation of these flavonoids with long-chain fatty acids (palmitic and oleic acids) catalyzed by CALB was performed. The authors reported that the type of anion had a greater influence on CALB activity than the cationic moiety. Ionic liquids containing $\mathrm{TF}_{2} \mathrm{~N}^{-}, \mathrm{PF}_{6}{ }^{-}$, and $\mathrm{BF}_{4}^{-}$ anions led to higher reaction rates ( $98 \%$ for TOMA $\cdot \mathrm{TF}_{2} \mathrm{~N}$ ), while those containing anions with strong solvating properties led to decreased yields. This fact was attributed to increased interactions with the protein structure of CALB [57].

In flavonoid acylation reactions, it is essential to limit the water content of the reaction medium in order to move the reaction equilibrium towards esterification and minimize hydrolysis. A little amount of water in the reaction medium is necessary to solvate the enzyme and to maintain its activity; however, if the water content is too high, it may decrease the yield of the reaction $[13,14]$. Our research group reported that, for the acylation of hesperidin with decanoic acid catalyzed by CALB, when the water content of the reaction medium increased from $<200 \mathrm{ppm}$ to higher than $550 \mathrm{ppm}$, the conversion rate decreased from 39.7 to $14.0 \%$ ( Fig. 6) [32].

The water content required for the catalytic process depends on the type and form of the enzyme (native or immobilized) and on the solvent $[58,59]$. In general, the optimal water content for esterification reactions in organic solvents ranges from 0.2 to $3.0 \%[49,60]$. High enzymatic activities for CALB may be achieved when the water content is about 200 ppm [10]. Some authors report that the optimal water content for biocatalysis in an organic medium is $0.05 \%(\mathrm{v} / \mathrm{v})$ [13], and high acylation rates may be reached when the initial water activity is 0.11 or less [14]. Limitations in the transport of hydrophobic substrates from the solvent through the water layer surrounding the enzyme may be responsible for the decrease of the conversion rate when the water content increases [61,62].

The addition of molecular sieves to the medium leads to a significant increase in the reaction yield $[8,13]$. Molecular sieves are composed of synthetic or natural aluminosilicates, arranged in a macro crystal structure with internal channels of defined sizes. The smallest diameters of the molecular sieves ( $3 \AA$ or $4 \AA$ ) are able to adsorb small molecules such as water, ammonia, and other gases to the structure [63].

\section{Nature and chain length of the acyl donor}

The nature and chain length of the acyl donor have a remarkable effect on the acylation reaction. Choosing a suitable acyl donor significantly influences the physicochemical and biological properties of the synthesized esters. The acyl donor should be preferably inexpensive, fast acylating, and nonreactive in the absence of the enzyme [64]. Several acylating agents have been tested in flavonoid ester synthesis reactions, such as aromatic or aliphatic organic acids, and the fatty acids have received particular attention for their ability to increase the solubility of these molecules in lipophilic systems [19].

The binding site of CALB is elliptical and narrow, similar to a funnel, with dimensions of $9.5 \times 4.5 \AA$. The longest fatty acid that completely fits in the enzyme core has $13 \mathrm{C}$. With the increase in the number of $C$ of a fatty acid or the increase in the size of the

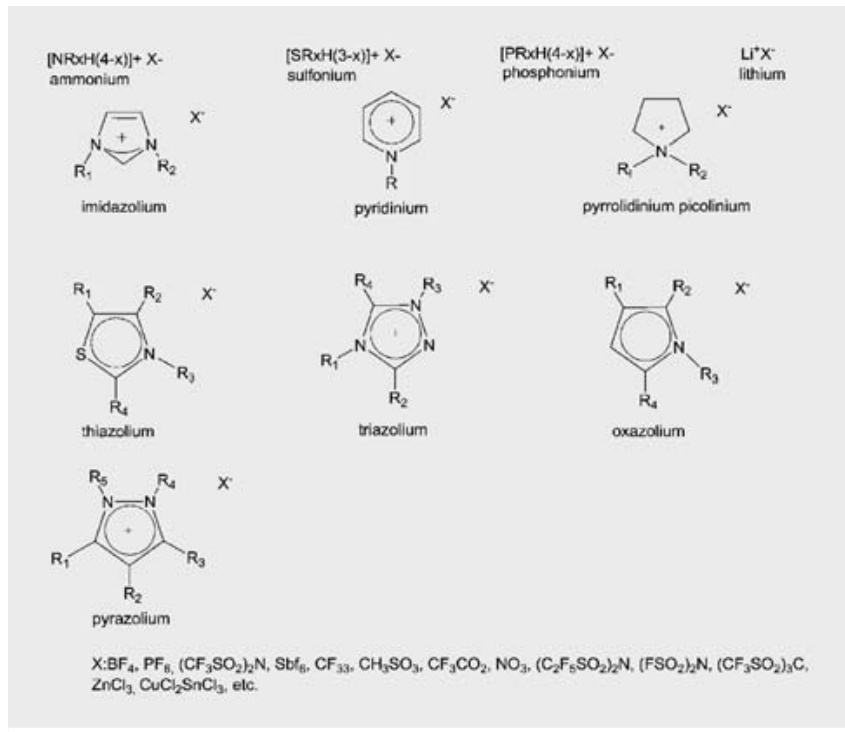

- Fig. 5 Examples of cations and anions in ionic liquids [53].

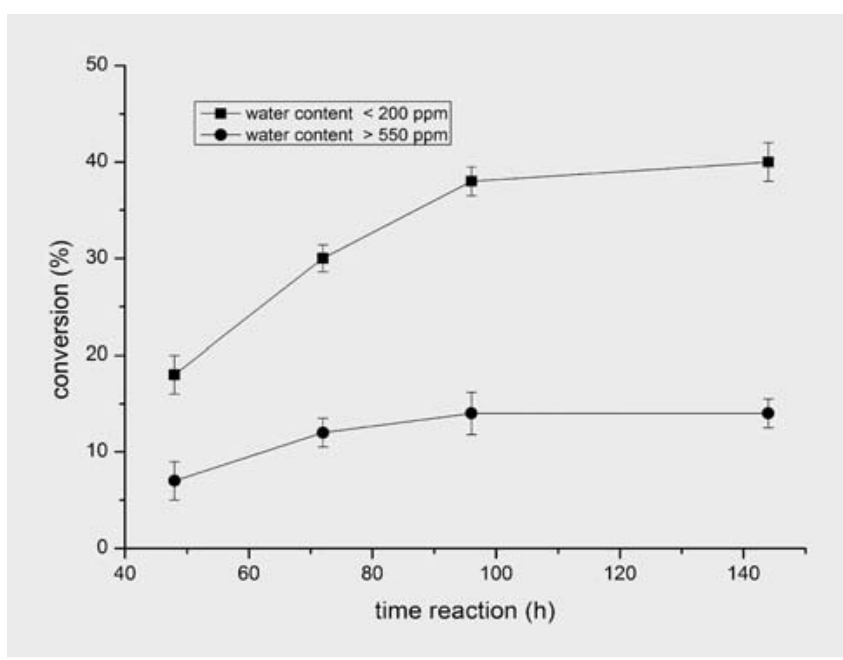

- Fig. 6 Reaction progress of the enzymatic acylation of hesperidin $(100 \mathrm{mM})$ with decanoic acid $(500 \mathrm{mM})$ catalyzed by immobilized CALB $(8.0 \mathrm{mg} / \mathrm{mL})$ in $\left[\mathrm{bmim}_{\mathrm{B}} \mathrm{BF}_{4}\right.$ and acetone $(5: 5, \mathrm{v} / \mathrm{v})$ at $50^{\circ} \mathrm{C}$ [32].

molecule, the steric hindrance leads to low reaction efficiency. Therefore, CALB is selective for short- and medium-chain fatty acids [65], as has been shown by some studies $[6,66]$. A better performance of CALB in the esterification of naringin and rutin was achieved when fatty acids containing up to $10 \mathrm{C}$ were employed. The $\log \mathrm{P}$ of the fatty acids may exert an influence on the acylation rates [66]. The use of esters as acyl donors may lead to higher conversion rates. Vinyl esters may lead to a faster reaction when compared to other esters [64]. - Table 2 summarizes some studies of the influence of the nature of the acyl donors and their chain lengths on the enzymatic acylation of flavonoids. 
- Table 2 Influence of the nature and acyl donor chain length on the enzymatic acylation of flavonoids.

\begin{tabular}{|c|c|c|c|}
\hline Flavonoid & Acyl donor & Reaction rate (\%) & Reference \\
\hline Naringin & FAs up to $4 \mathrm{C}$ & $65(a)$ & \multirow[t]{2}{*}{ [6] } \\
\hline Rutin & vinyl laurate & $23(a)$ & \\
\hline \multirow[t]{6}{*}{ Naringin } & decanoic acid & 20.0 (b), 25.0 (c) & \multirow[t]{6}{*}{ [8] } \\
\hline & lauric acid & 23.0 (b), 27.0 (c) & \\
\hline & stearic acid & 19.0 (b), $22.0(\mathrm{c})$ & \\
\hline & vinyl decanoate & 54.0 (b), 65.0 (c) & \\
\hline & vinyl laurate & 59.0 (b), 70.0 (c) & \\
\hline & vinyl stearate & 48.0 (b), 58.0 (c) & \\
\hline \multirow[t]{2}{*}{ Isoquercitrin } & ethyl butyrate & $66(d)$ & \multirow[t]{2}{*}[38]{} \\
\hline & ethyl stearate & $38(d)$ & \\
\hline \multirow[t]{3}{*}{ Rutin } & octanoic acid & 14.8 (b), 17.7 (c) & \multirow[t]{3}{*}{ [69], [14] } \\
\hline & decanoic acid & 24.0 (b), 22.0 (c) & \\
\hline & dodecanoic acid & 13.5 (b), 23.0 (c) & \\
\hline \multirow[t]{3}{*}{ Naringin } & octanoic acid & 19.6 (b), 30.1 (c) & \multirow[t]{3}{*}{ [69], [14] } \\
\hline & decanoic acid & 21.9 (b), 18.3 (c) & \\
\hline & dodecanoic acid & 18.2 (b), 15.8 (c) & \\
\hline
\end{tabular}

Reaction media: (a) ionic liquids, (b) tert-butanol, (c) acetone, (d) 2-methyl-2-butanol

However, the effect of the carbon chain length of the FAs is still a matter of debate. In the acylation of rutin with CALB using free fatty acids with 6 to $18 \mathrm{C}$, the results showed that for fatty acids with up to $12 \mathrm{C}$ the conversion rates rose with the increase in the chain length, while for fatty acids with larger chains there was no significant difference [10]. Another study reported that the length of the fatty acid carbon chain showed no significant effect on conversion rates when medium and long-chain fatty acids were used [14], while for the acylation of isoquercitrin catalyzed by CALB, the initial reaction rates were similar for acyl donors having 4 to $12 \mathrm{C}$ (around $17 \times 10^{-3} \mathrm{mmol} / \mathrm{h}$ ) [38]. Other authors have found no influence of the acyl donor chain length on the acylation of naringin by fatty acids or their vinyl esters [7].

\section{Acyl donor/flavonoid molar ratio}

The acyl donor/flavonoid molar ratio exerts significant influence in the acylation reaction. The excess of acyl donor can lead to higher conversion rates [67]. As the amount of ester formed is controlled by the equilibrium of the reaction, the excess of one of the substrates increases the yield based on the limiting reagent [68]. In flavonoid acylation reactions, the excess reagent is typically the acylating agent, due to its low cost and availability.

Several reports have been trying to determinate the best molar ratio for achieving higher conversion rates. Generally, molar ratios from 5: 1 to 15:1 (acyl donor/flavonoid) have been studied. Many authors reported that $5: 1$ is the most efficient ratio for flavonoid acylation reactions $[7,13,69,70]$, but other ratios have also been reported such as 7:1 [32] and 15:1 [6]. This fact may be attributed to interactions between the acyl donor/flavonoid molar ratio and other factors that influence the acylation reaction. In fact, when studying the optimization of the enzymatic acylation of hesperidin with decanoic acid via Response Surface Methodology, our research group found that there was a significant interaction $(p<0.1)$ between the acyl donor/flavonoid molar ratio and the composition of the reaction medium ([bmim]BF $4 /$ acetone ratio, v/v) [32].

A literature report indicates that the acylation of quercetin using CALB at $60^{\circ} \mathrm{C}$ occurred at positions $3^{\prime}-\mathrm{OH}$ and $4^{\prime}-\mathrm{OH}$ of the $\mathrm{B}$ ring, leading to the formation of $4^{\prime}$-O-acetyl quercetin and $3^{\prime}$-Oacetyl quercetin, in a proportion of $1: 3$, respectively [23]. The presence of a single phenolic group in the $B$ ring of naringenin (position $4^{\prime}$ ) led to the formation of a single product, 4'-O-acetyl naringenin, while the absence of the double bond in the $\mathrm{C2}-\mathrm{C} 3$ position of the $B$ ring of the flavonoid brought about increased flexibility, leading to higher acylation rates (71\%). Although most studies indicate that higher rates of bioconversion are achieved when an excess of acyl donor is employed, the authors used a small excess of flavonoids relative to the acyl donor (vinyl acetate), in a ratio of $3: 1$ [23].

\section{Temperature}

Temperature represents a significant factor in enzyme-catalyzed reactions, due to its influence on the viscosity of the reaction medium, on the activation and thermal inactivation of the enzyme and on the solubility of the substrates.

Since CALB is a thermostable enzyme, higher temperatures may increase its catalytic activity [58]. There are literature reports on the lipase-catalyzed acylation of flavonoids at temperatures ranging from 30 to $100{ }^{\circ} \mathrm{C}$ [49]. Often, the best enzymatic activity is achieved when acylation is performed at temperatures around $60^{\circ} \mathrm{C}$, which allows for good solubility of the substrates and, thereafter, higher conversion rates $[6,9,10,12,13,39,40,60,71,72]$.

Increasing the reaction temperature may help to reduce mass transfer limitations. This effect has been described for the acylation of commercial rutin and esculin with palmitic and oleic acids catalyzed by CALB in ionic liquid media [57].

Temperature may affect the stability of the enzyme. After 1 day of incubation at $80^{\circ} \mathrm{C}$ during the acylation of phloridzin, there was a decrease by $30 \%$ in CALB activity, which was attributed to enzyme denaturation and to a possible interaction between ethyl cinnamate and CALB [12].

\section{Methods to improve the reaction time of the recovery of acylated flavonoids}

Recently, methods such as microwave irradiation and ultrasound have been considered as effective tools in synthetic organic chemistry and green chemistry. Both methods are efficient in increasing reaction rates and yields $[73,74]$.

Microwave irradiation in a solvent-free system was employed in the acylation of isoquercitrin and phloridzin with long-chain saturated, mono-, and polyunsaturated fatty acids catalyzed by CALB. The authors described this method as being more efficient and economical, in terms of time and energy, than the conventional reaction condition. In the conventional method, the reaction took 18-24 h. In the microwave-assisted solution phase method, the reactions took just $120-160$ s, and for the microwave-irradiated solvent-free reactions, the reaction time was completed in 75- 
$105 \mathrm{~s}$, and no significant difference in the percentage yield was noticed in any of those cases. The authors conclude that the enzyme activity, selectivity, and stability can be modified by microwave heating because polar groups of enzymes, such as hydroxyls and $\mathrm{NH}_{2}$, can absorb the microwave energy [75]. Changes in enzymatic properties induced by microwaves are due to the transference of microwave energy between the electromagnetic field and the polar structural profile, which improves the flexibility of the enzyme [76]. Polar substrates of the enzyme may absorb the microwave irradiation, enhancing the reactivity of the functional groups involved in the enzymatic reaction [77].

Ultrasound technology may increase interactions between phases by cavitations resulting from the collapse of bubbles. The ultrasonic jet improves emulsification [78] and results in an increase in mixing and mass transfer in the emulsions [79]. A recent literature report compared an alternative method using sonication with the conventional reaction method for the lipase-catalyzed acylation of isoquercitrin and phloridzin with fatty acids (C14-C18) catalyzed by CALB. The study reported that sonication reduced the time required by 4 - to 5 -fold, and the CALB showed no deactivation at the optimum temperature $\left(40-45^{\circ} \mathrm{C}\right)$ [80].

\section{Impact of Acylation on Biological Activities}

Some studies have revealed that by introducing lipophilic molecules to the basic flavonoid skeleton, not only can the physicochemical properties be modified, but also the biological effects of flavonoids are improved. - Table 3 provides an up-to-date overview of selected, tested biological activities of flavonoid derivatives synthesized by lipases.

\section{Antioxidant activity}

Many studies have shown an inverse correlation between the intake of food rich in flavonoids and the development of cardiovascular disorders, cancer, and other diseases associated with aging. These beneficial health effects have been attributed to the flavonoids' antioxidant activity, which is related to their ability to reduce free radical formation and to scavenge free radicals [50]. In the last few years, the natural phenolic compounds found in vegetables and fruits have gained interest both as alternative antioxidants in foods [81] and as functional ingredients [82].

Many literature reports show that the antioxidant activity of flavonoids and their tendency to inhibit free radical-mediated events depend on their chemical structure. Moreover, the biological activity of flavonoids depends on their lipophilicity. The degree of lipophilicity influences the ability of the flavonoid to reach the true site of the free radical attack, modulating its interaction with proteins, enzymes, and specific cell types [6].

The modification of their physicochemical properties by acylation may exert a positive influence on the entry of polyphenols into enterocytes and thus on their bioavailability [27]. The enzymatic acylation of flavonoids by lipases with phenolic acids is more regioselective than chemical acylation and may enhance not only their solubility in various media but also their stability and their antioxidant activity [18]. In the last decades, many researchers have studied the antioxidant activity of lipase-acylated flavonoids and some of the most recent publications in this area are listed below.
The antioxidant activity of natural flavonoid glycosides isolated from Greek endemic plants in an isolated LDL and total serum model in vitro was improved by enzymatic acylation [8].

There was a significant increase of antioxidant activity for rutin-4"'-O-oleate compared to non-acylated rutin [4]. The enzymatic acylation of rutin with vinyl laurate (C12:0) did not affect its antioxidant capacity, whereas acylation with vinyl stearate (C18:0) decreased the antioxidant activity of rutin in LDL oxidation. These results show that other mechanisms, apart from the increase in the degree of lipophilicity, may also influence the antioxidant activity of flavonoids. These mechanisms are related to the structure of the acyl donor, such as the presence of unsaturated bonds, and suggest that a new class of potential antioxidants may be synthesized by enzymatic acylation of flavonoids with oleic acid. Moreover, this study demonstrated for the first time that ionic liquids might be advantageous reaction media for the one-step enzymatic synthesis of flavonoid glycoside derivatives with increased lipophilicity [4].

A study of rutin and its acylated esters reported a lowered ability of rutin laurate and rutin palmitate to bind metals and to prevent lipid oxidation compared to rutin; however, these rutin esters protected LDL cholesterol from oxidation in vitro more effectively. Furthermore, rutin and rutin esters exhibited relatively strong radical scavenging abilities. Thus, this report concludes that the acylation of rutin with medium- or long-chain fatty acids may result in improved antioxidant abilities [57].

Literature reports found that the acylation of rutin with unsaturated fatty acids, such as oleic, linoleic and linolenic acid, increased the antioxidant potential of the initial compound [6,39].

Isoquercitrin derivatives with different fatty acids were evaluated regarding their antioxidant activity over four antiradical experiments. The acylated derivatives showed higher xanthine oxidase $(\mathrm{XO})$ inhibition activities than the parent substance. Also, all isoquercitrin esters showed similar or higher activity against ABTS radicals compared to isoquercitrin, but decreased it against DPPH and superoxide radicals. In general, isoquercitrin esters were shown to exhibit an antioxidant activity that depended on the acyl chain length [38]. The same authors observed that the enzymatic acylation of isorhamnetin-3-O-glucoside with ethyl laurate and ethyl butyrate increased their ability to inhibit XO but lowered their ability to scavenge free radicals [42].

The evaluation of isoquercitrin and its derivatives obtained through esterification with six selected long-chain fatty acids indicated that the synthesized compounds were more effective in inhibiting both primary and secondary oxidation in oil-in-water emulsions than isoquercitrin. However, isoquercitrin was more effective in bulk oil, whereas the modified compounds were not effective [83].

Prunin esterification with aliphatic molecules preserved the antiradical activity of the flavanone glucoside parent and notably increased the derivatives' solubility in the hydrophobic medium 1octanol, making them suitable for use in hydrophobic matrices in the food, cosmetic, and pharmaceutical industries [44].

The acylation of isoorientin and isovitexin significantly improved their lipophilicity, but reduced their antiradical activity [84]. This data is in accordance with another report about the antioxidant activity of isoorientin-acylated derivatives, which 
- Table 3 Biological properties of acylated flavonoid derivatives biosynthesized by lipases.

\begin{tabular}{|c|c|c|c|}
\hline Flavonoid & Acyl donor & Biological Effect & Reference \\
\hline Rutin & Oleic & $\uparrow$ Antioxidant & [6] \\
\hline Rutin, naringin & Oleic, linolenic and linoleic acids, ethyl linoleate & $\uparrow$ Antiangiogenic, $\uparrow$ Anticancer & [7] \\
\hline $\begin{array}{l}\text { Chrysoeriol-7-O- } \beta \text {-D-(3"-E-p-cou- } \\
\text { maroyl)-glucopyranoside,chryso- } \\
\text { eriol-7-[6"'-O-acetyl- } \beta \text {-D-allosyl- } \\
(1 \rightarrow 2)-\beta \text {-D-glucopyranoside] }\end{array}$ & Vinyl laurate & $\uparrow$ Antioxidant (LDL oxidation), $\uparrow$ Antibacterial & [8] \\
\hline Silybin & Butyric and lauric acids & $\uparrow$ Antiangiogenic, $\uparrow$ Anticancer & {$[20]$} \\
\hline Isoquercitrin & $\begin{array}{l}\text { Ethyl butyrate, caproate, caprylate, decanoate, } \\
\text { laurate, palmitate, stearate, oleate }\end{array}$ & $\begin{array}{l}\uparrow \text { Inhibition of xanthine oxidase, } \uparrow \text { Anticancer, } \\
\uparrow \text { Antioxidant (ABTS radical), } \downarrow \text { Antioxidant (DPPH } \\
\text { and superoxide radicals) }\end{array}$ & [38] \\
\hline Rutin & $\begin{array}{l}\text { Butyric, capric, caprylic, decanoic, lauric, myristic, } \\
\text { palmitic, stearic, oleic, linoleic and linolenic acids }\end{array}$ & $\begin{array}{l}\leftrightarrow \text { Antioxidant (DPPH radical and } \beta \text {-carotene } \\
\text { linoleate method), } \uparrow \text { Lipophilicity }\end{array}$ & [39] \\
\hline Silybin & Dicarboxylic acids & $\uparrow$ Antiangiogenic, $\uparrow$ Anticancer & [41] \\
\hline Isorhamnetin-3-O-glucoside & Ethyl butyrate, ethyl laurate & $\begin{array}{l}\uparrow \text { Inhibition of xanthine oxidase, } \uparrow \text { Anticancer, } \\
\downarrow \text { Antioxidant (DPPH radical and superoxide radical } \\
\text { scavenging) }\end{array}$ & [42] \\
\hline Prunin & Lauric & $\leftrightarrow$ Antioxidant & [44] \\
\hline Phloridzin, isoquercitrin & $\begin{array}{l}\text { oleic, stearic, linoleic, linolenic, eicosapentaenoic } \\
\text { and docosahexaenoic acids }\end{array}$ & $\begin{array}{l}\uparrow \text { Inhibition of tyrosinase, } \downarrow \text { Antioxidant (DPPH } \\
\text { radical, FRAP and ORAC assays) }\end{array}$ & [48] \\
\hline Rutin, esculin, phloridzin & $\begin{array}{l}\text { Butyric, capric, caprylic, decanoic, lauric, myristic, } \\
\text { palmitic, stearic, oleic, linoleic, linolenic, arachi- } \\
\text { donic and erucic acids }\end{array}$ & $\begin{array}{l}\uparrow \text { Inhibition of serine proteases trypsin, thrombin, } \\
\text { elastase and urokinase }\end{array}$ & [49] \\
\hline Rutin & Lauric and palmitic acids & $\begin{array}{l}\uparrow \text { Antioxidant (LDL-oxidation), } \downarrow \text { Antioxidant } \\
\text { (DPPH radical, } \mathrm{Fe}^{3+} \text { reducing power and iron } \\
\text { chelating) }\end{array}$ & [57] \\
\hline Isoquercitrin & $\begin{array}{l}\text { Stearic,oleic, linoleic, linolenic, eicosapentaenoic, } \\
\text { docosahexaenoic }\end{array}$ & $\uparrow$ Antioxidant (fish oil and LDL oxidation) & [83] \\
\hline Isoorentin, Isovitexin & Lauric, myristic and palmitic acids & $\begin{array}{l}\uparrow \text { Lipophilicity, } \downarrow \text { Antioxidant (DPPH radical and } \\
\text { superoxide radical scavenging) }\end{array}$ & [84] \\
\hline Isoorentin, Isovitexin & Palmitic acids & $\downarrow$ Antioxidant (DPPH radical) & [85] \\
\hline Phloridzin & $\begin{array}{l}\text { Oleic, caproic, myristic, palmitic, stearic, capric, } \\
\text { linoleic }\end{array}$ & $\downarrow$ Antioxidant & [86] \\
\hline (-)-epigallocatechin-3-O-gallate & Vinyl acetate & $\uparrow$ Antioxidant & [87] \\
\hline Phloridzin & $\begin{array}{l}\text { Stearic,oleic, linoleic, linolenic, eicosapentaenoic, } \\
\text { docosahexaenoic }\end{array}$ & $\uparrow$ Anticancer & [91] \\
\hline Isoquercitrin & $\begin{array}{l}\text { Stearic, oleic linoleic, linolenic, eicosapentaenoic, } \\
\text { docosahexaenoic acids }\end{array}$ & $\uparrow$ Anticancer & [92] \\
\hline Isoquercitrin & $\begin{array}{l}\text { Stearic, oleic, linoleic, linolenic, eicosapentaenoic } \\
\text { and docosahexaenoic acids }\end{array}$ & $\uparrow$ Anticancer & [93] \\
\hline Isoquercitrin & $\begin{array}{l}\text { Linolenic, eicosapentaenoic and docosahexaenoic } \\
\text { acids }\end{array}$ & $\begin{array}{l}\uparrow \text { Anticancer, } \uparrow \text { Antioxidant (lipid hydroper- } \\
\text { oxides), } \uparrow \text { Anti-inflammatory }\end{array}$ & [94] \\
\hline Isoquercitrin & Eicosapentaenoic acid & $\uparrow$ Anti-inflammatory & [107] \\
\hline Phloridzin & Docosahexaenoic acid & $\uparrow$ Anti-inflammatory & [108] \\
\hline Quercetin & Acyl groups (C2-C14) & $\leftrightarrow$ Antimicrobial, $\uparrow$ Inhibition of lipase, $\downarrow$ Anti-HIV & [115] \\
\hline $\begin{array}{l}\text { Naringin, hesperidin, neohesperidin, } \\
\text { hesperetin glucoside }\end{array}$ & Butyrate, decanoate, laurate & $\uparrow$ Antifungal & [116] \\
\hline Flavonoids from C. limetta & Tributyrin & $\uparrow$ Antifungal & [117] \\
\hline Rutin & $\begin{array}{l}\text { Palmitic, oleic, linoleic, linolenic, arachidonic, } \\
\text { erucic }\end{array}$ & $\begin{array}{l}\uparrow \text { Antioxidant, } \uparrow \text { Inhibition of sarco/endoplasmic } \\
\text { reticulum Ca2+-ATPase }\end{array}$ & [132] \\
\hline Phloridzin & Long-chain fatty acids (C18-C22) & $\begin{array}{l}\uparrow \text { Inhibition of rennin, } \uparrow \text { Inhibition of angiotensin } \\
\text { converting enzyme }\end{array}$ & [133] \\
\hline
\end{tabular}

Symbol: $\uparrow$ increased, $\downarrow$ reduced, $\leftrightarrow$ no effects (maintains the activity) 
shows that the derivatives exhibited less radical scavenging activity than their parental form isoorientin. Specifically, the esters exhibited less DPPH radical scavenging activity. This may be explained by the increased volume and steric hindrance after acylation, making it more difficult for acylated derivatives to reach radical active sites [85].

Higher free radical scavenging abilities for the parental compounds were also reported for the acylation of phloridzin and isoquercitrin, although from the bioactivity point of view, all esters retained substantial antioxidant capacity after the esterification. In a similar way, another group reported that esters of phloridzin generally have poorer antioxidant capacities than their parent flavonoid. The highest free radical scavenging capacity was found in phloridzil myristate, while phloridzil acetate and stearate were found to have the lowest antioxidant activities. Additionally, when the effect of the saturation level of acyl donors (stearic, oleic, and linoleic acids) on the antioxidant capacity were compared, it was shown that phloridzil oleate had the best antioxidant properties. Although esters presented weaker antioxidant activity compared to pure phloridzin, they were also more lipophilic, which makes them more efficient in hydrophobic media [86].

Acylated derivatives of (-)-epigallocatechin-3-O-gallate (EGCG) showed higher lipophilicity than EGCG, as confirmed by their octanol-water partition coefficients. The acylated derivatives also presented better antioxidant activity than EGCG, as determined by peroxide values in sunflower oil. Acylated EGCG also exhibited the highest DPPH radical scavenging activity compared to the original molecule [87].

\section{Antiproliferative and citoprotection activities}

Studies performed in recent years have proved that flavonoids are able to inhibit tumor cell proliferation, to stop tumor growth, and to actively participate in inhibiting carcinogenesis. They have been reported to interfere in the initiation, promotion, and progression of cancer by modulating different enzymes and receptors in signal transduction pathways related to cellular proliferation, differentiation, apoptosis, inflammation, angiogenesis, metastasis, and reversal of multidrug resistance. In the advanced stage of tumor growth, flavonoids are able to suppress the process by inhibiting DNA synthesis and angiogenesis, as well as inducing apoptosis of tumor cells [88, 89].

Flavonoids and their synthetic analogues have been intensely investigated for the treatment of ovarian, breast, cervical, pancreatic, and prostate cancer [90]. Attention has been focused, over recent years, on lipase-catalyzed acylated flavonoids that present anticarcinogenic activity, and some of the most recent publications in this area are listed below.

Evidence shows that enzymatic esterification of rutin with different mono- and poly-unsaturated fatty acids catalyzed by CALB lipase was able to decrease the production of vascular endothelial growth factor (VEGF) by K562 human leukemia cells, even though the parental molecules were inactive, indicating that these novel compounds might possess improved antiangiogenic and antitumor properties $[7,20]$.

Isoquercitrin esters exhibited a dose-dependent, antiproliferative action on $\mathrm{CaCO} 2$ cells and were more active than parental isoquercitrin. Esters with acyl chain lengths from C8 to C16 showed the greatest activity. However, no relationship between the acyl chain length and the antiproliferative action on $\mathrm{Caco} 2$ cells could be established. The authors explained that the activity of a compound in a biological system depends on its interaction with cell membranes, due to its lipophilicity, and also on its affinity for specific cell receptors [38].

The same research group evaluated the antiproliferative effect of isorhamnetin-3-O-glucoside laurate and butyrate, obtained by the regioselective chemoenzymatic acylation of isorhamnetin-3$O$-glucoside using CALB, on colon cancer cells. The results showed that isorhamnetin-3-O-glucoside laurate, with a long carbon chain (C12), was more efficient than isorhamnetin-3-O-glucoside butyrate (C4) [42].

The antiproliferative effect of silybin derivatives on K562 (leukemia) cells was also reported $[20,41]$. The acylation of silybin with hexadecanedioic acid (C16) catalyzed by CALB led to the synthesis of a new derivative that was a more potent inhibitor of cell proliferation compared to silybin in all test concentrations and incubation times. Furthermore, the esters of silybin with dodecanedioic or hexadecanedioic acid significantly downregulated the levels of secreted VEGF (one of the key angiogenic growth factors secreted from tumor cells) and exhibited greater efficiency compared to silybin. Other silybin derivatives, silybin-23-0-butyrate and silybin-23-O-laurate, were also potent inhibitors of K562 cell proliferation, but they did not present a better effect than the precursor $[20,41]$.

More recently, a study reported that the anticarcinogenic effect of fatty acid esters of phloridzin was distinctly more potent than their corresponding parent molecules on hepatocellular carcinoma (HepG2), breast adenocarcinoma (MDAMB-231), and acute monocytic leukemia (THP-1) [91].

Inhibition of hepatocellular carcinoma (HepG2 cells) by longchain acylated esters of isoquercitrin was also investigated, and the authors reported that acylated isoquercitrin inhibited HepG2 proliferation by $85-90 \%$ after 6 and $24 \mathrm{~h}$ of treatment, respectively. Cell death was attributed to cell cycle arrest and apoptosis, observed by DNA fragmentation, fluorescent microscopy, high caspase-3 activity, and DNA topoisomerase II inhibition. Acylated isoquercitrin also showed low toxicity for normal liver cells when compared to Sorafenib, a chemotherapy drug for hepatocellular carcinoma. Oleic acid esters of isoquercitrin were considered by the authors to be the best candidates for anticancer therapy [92].

Long-chain fatty acid derivatives of isoquercitrin with stearic, oleic, linoleic, linolenic, eicosapentaenoic, and docosahexaenoic acids were synthesized using CALB lipase and evaluated for their potential in protecting human lung fibroblasts against cytotoxicity induced by smoke toxicants 4-(methylnitrosoamino)-1-(3pyridinyl)-1-butanone,benzo- $\alpha$-pyrene, nicotine, and chromium. Acylated derivatives of isoquercitrin were effective in protecting against nicotine- and chromium-induced cell death and membrane lipid peroxidation [93].

Acylated derivatives of isoquerctitrin with linolenic, eicosapentaenoic, and docosahexaenoic acids also showed high cytoprotective effects on cell culture models under $\mathrm{H}_{2} \mathrm{O}_{2}$-induced oxidative stress. These compounds led to higher cell viability in human lung fibroblasts (WI-38) and human primary hepatocytes when compared to the control. Oleic acid and linoleic acid derivatives of iso- 
quercitrin showed cytoprotective activity in human primary hepatocites, and all the derivatives of isoquercitrin and quercetin were more effective in lowering the production of lipid hydroperoxides than the control. Linolenic and docosahexaenoic acid derivatives of isoquercitrin were more effective in inhibiting lipid hydroperoxidation than isoquercitrin and quercetin. Fluorescence microscopy studies showed that $\mathrm{H}_{2} \mathrm{O}_{2}$-induced apoptosis was attenuated by the acylated derivatives of isoquercitrin. The authors concluded that the acylated derivatives have better cytoprotective effects than isoquercitrin, and the concentration of these compounds should be selected to avoid cytotoxicity [94].

\section{Anti-inflammation}

Due to significant in vitro and in vivo activities, flavonoids are considered to be promising candidates for new anti-inflammatory drugs. An important mechanism for anti-inflammatory activity is inhibition of eicosanoid-generating enzymes, including phospholipase A2, cyclooxygenases, and lipoxygenases, thereby reducing the concentrations of prostanoids and leukotrienes. Other mechanisms include the inhibition of histamine release, phosphodiesterase, protein kinases, and transcriptase activation [95].

Previous research has shown that chemical acylation and alkylation of the natural products, including flavonoid derivatives, can be carried out with high efficiency and that the derivatives show significant biological activity. Most articles report the use of chemical synthesis for new acylated flavonoids with anti-inflammatory action [96-100] and there is little published data reporting the application of biocatalysis in the synthesis of esters of acylated flavonoids. Nevertheless, it is clear that acyl derivatives of diosmetin and hesperetin constitute an interesting template for the evaluation of new anti-inflammatory agents and may be helpful for designing new therapeutic tools against inflammation [96]. The 6"-O-esterification of kaempferol-3-O-glucoside (astragalin) with $p$-coumaric acid has been found to increase its anti-inflammatory activity 8 times compared to the initial flavonoid, while the addition of another p-coumaroyl group at the 2 " position resulted in activity 30 times greater than that of astragalin [101].

Esters of flavonoids with omega-substituted C6 to C22 fatty acids have the property of protecting skin cells against damage caused by UVA and UVB radiation [102] in a more effective manner than the flavonoids alone. Moreover, these esters demonstrated their ability to stimulate the glutathione metabolism of human skin cells after UVA irradiation, i.e., to stimulate their cellular defenses. They also have anti-inflammatory and soothing properties, as demonstrated by the inhibition of released protein kinase $\mathrm{PGE}_{2}$ after UVB irradiation. Thus, these flavonoid esters may be used to protect the skin and scalp and/or to fight against UV and sun damage, sunburn, erythema, mitochondrial, or nuclear DNA damage and to prevent or fight photoaging, providing improvements in signs of aging such as wrinkles, elasticity loss, and decreased skin thickness [102].

On the other hand, chemical 7-O-alkylation of isoflavonoids had an adverse effect on their anti-inflammatory activity [103]. Among the chrysin derivatives, only 5,7-diacetylflavone showed inhibitory activity against cyclooxygenase- $2\left(\mathrm{IC}_{50}=2.7 \mu \mathrm{M}\right)$, while chrysin showed no effect at all [104].
Phytochemical investigation of the leaves of Tipuana tipu (Benth.) Lillo led to the isolation of a new acylated kaempferol tetraglycoside (kaempferol 3-O- $\alpha$-L- rhamnopyranosyl- $(1 \rightarrow 6)-O-[\beta$ D-glucopyranosyl-( $1 \rightarrow 2)$-4-O-acetyl- $\alpha$-L-rhamnopyranosyl-

$(1 \rightarrow 2)]-\beta$-D-galactopyranoside). The results of the anti-inflammatory activity investigation revealed that the length of the oligosaccharide residue has a great influence on it, and also the presence of an additional phenolic group in the aglycone moiety causes an increase in the activity [105].

Derivatives of cyanidan-3-ol with organic carboxylic acid, carbonic acid, and sulphonic acid were described in regard to their activity in the prevention of hepatic necrosis and lipoperoxidation. These compounds could protect the tissue by inhibiting the degradation of collagen by collagenase [106].

The influence of the acylation of isoquercitrin with eicosapentaenoic acid on hyperlipidemia and inflammation was assessed in vitro and in vivo. The acylated compound was more effective in reducing the production of TNF- $\alpha$, prostaglandin 2, and cyclooxygenase (COX)-2 levels and the nuclear expression of nuclear factor-kappa B (NF- $\kappa$ B) after lipopolysaccharides induced inflammation in THP-1-derived macrophages when compared to the original molecules and commercial drugs. Serum HDL cholesterol was higher and hepatic total cholesterol was lower in rats fed with high-fat diet supplemented with acylated quercetin. Furthermore, serum concentrations of C-reactive protein (CRP), interleukin-6, and interferon-gamma (IFN- $\gamma$ ) were significantly lower in the group fed with the diet supplemented with acylated isoquercitrin compared to the group fed with a high-fat diet [107].

Inhibition of lipopolysaccharide-induced inflammation in THP1-derived macrophages by acylated esters of phloridzin with docosahexaenoic acid was also studied. Pre-exposure of phloridzin esters was more effective in reducing TNF- $\alpha$, interleukin-6, and COX-2 levels than docosahexaenoic acid and nimesulide (COX inhibitor drug). Acylated phloridzin and docosahexaenoic acid were the most effective inhibitors of NF- $\kappa B$ [108].

Acylated derivatives of isoquercitrin with stearic, oleic, linoleic, linolenic, eicosapentaenoic, and docosahexaenoic acids were evaluated for their anti-inflammatory activity in human lung fibroblasts. Based on the evaluation of inflammatory markers, such as COX-2 and prostaglandin $E_{2}$, the acylated derivatives were effective in reducing the inflammatory response [94].

\section{Antibacterial and antifungal activities}

Among the flavonoids with antimicrobial activity described in the literature, we can highlight apigenin, galangin, pinocembrin, ponciretin, genkwanin, naringin, and naringenin, epigallocatechin gallate and its derivatives, kaempferol and its derivatives, luteolin and luteolin 7- glucoside, quercetin, 3-O-methylquercetin various quercetin glycosides, and sophoraflavanone $G$ and its derivatives.

Quercetin, at high concentrations, appeared active against different microorganisms including Bacillus subtilis, Micrococcus luteus, Staphylococcus aureus, and Staphylococcus epidermidis [109], Aspergillus flavus and Aspergillus parasiticus [110].

Recent chemistry studies have identified several structural features that improve the antibacterial properties of flavonoids. Esterification allows the addition of an acyl group in the molecule of a flavonoid at the reactive hydroxyl group, which may stabilize 
phenol function and increase compound lipophilicity, thereby enhancing the antimicrobial activities of the flavonoids.

Substitution of the gallate group of epicatechin gallate with 3$\mathrm{O}$-acyl chains of varying lengths (C4-C18) led to enhanced antistaphylococcal activity with chain lengths of C8 (octanoyl) and C10 (decanoyl) [111].

The vinyl ester of lauric acid of chrysoeriol-7-[6"'-O-acetyl- $\beta$-Dallosyl-( $1 \rightarrow 2)-\beta$-D- glucopyranoside, isolated from Greek endemic plants and synthetized by $C$. antarctica lipase, had higher antibacterial activity against two gram-positive bacteria, S. aureus and Bacillus cereus, compared to the unmodified flavonoid. That was attributed to their higher lipophilicity [8]. The enzymatic addition of a hydrophobic chain (such as the dodecyl moiety) to flavonoids is expected to increase their ability to interact with the cell membrane or even to penetrate it [112].

Chemical alkylation of (-)-epigallocatechin gallate dramatically improved the activity of this compound against gram-positive pathogens. The derivative 3-O-decyl-(+)-catechin was 64- to 128 -fold more active than its parent structure, with MICs of $1.0 \mu \mathrm{g} / \mathrm{mL}$ and $2.0 \mu \mathrm{g} / \mathrm{mL}$ against S. aureus and Enterococcus faecalis, respectively [113].

Additionally, the in vivo antimicrobial activity of certain natural substances could be due to their ability to interfere with virulence factors, such as lipase [114]. An interesting inhibitory activity on Candida rugosa lipase was described for quercetin $\left(I_{16}=10^{-4} \mathrm{M}\right)$ and especially its esters (3-O-acylquercetines, $\quad \mathrm{IC}_{16}=10^{-4}$ $\left.10^{-6} \mathrm{M}\right)$. In vivo, this inhibition could play an important role against lipase-producing microorganisms [115].

On the other hand, neither quercetin nor 3-O-acylquercetines (up to $100 \mathrm{mg} / \mathrm{mL}$ ) had any significant antimicrobial activity on the gram-positive strains (S. aureus, B. subtilis, Listeria ivanovi, Listeria monocytogenes, Listeria serligeri), gram-negative strains (Escherichia coli, Shigella flexneri, Shigella sonnei, Salmonella enteritidis, Salmonella tiphymurium), or yeasts (Candida albicans and Candida glabrata). The authors confirmed the anti-HIV activity of quercetin ( $80 \%$ inhibition at $40 \mathrm{mM}$ ), which seems to depend on the free hydroxyl in the $\mathrm{C}-3$ position, as suggested by the lack of activity of the 3-O-acylquercetines [115].

The antifungal activity of four flavonoids, isolated from citrus fruits, and their derivatives esterified with butyric, decanoic, and lauric acid was assessed. Experiments have shown that lipophilic derivatives more effectively inhibited growth of the food contaminant micromycetes A. parasiticus, A. flavus, Fusarium semitectum, and Penicillium expansum than the original unmodified molecules [116].

Lipase-catalyzed modification of flavonoids from Citrus limetta in the presence of the acyl donor tributyrin increases the antifungal activity of the compounds. The treated sample showed a $56.52 \%$ increase in the zone of inhibition against Candida albicans as compared to the control sample. Moreover, the zone of inhibition for the treated sample was significantly larger than that of fluconazole [117]. Also, enzymatically modified flavonoids can serve as a natural substitute to solve the problem of fluconazoleresistant Candida infections [118].

\section{Enzyme inhibitors}

Current knowledge suggests that polyphenolic compounds have the ability to selectively inhibit a wide range of enzymes. Inhibitory effects of polyphenols, including flavonoids, on various enzymes have been reported as well as that the degree of lipophilicity played a major role in improving enzyme inhibitory activities.

$\mathrm{XO}$ is an enzyme involved in purine metabolism that catalyzes the oxidation of hypoxanthine and xanthine to uric acid, generating the superoxide radical $\left(\mathrm{O}_{2}^{-}\right)$, which is involved in processes like inflammation, atherosclerosis, cancer, and aging [119]. During the reoxidation of $\mathrm{XO}$, molecular $\mathrm{O}_{2}$ acts as an electron acceptor, producing $\mathrm{O}_{2}^{-}$radicals and hydrogen peroxide $\left(\mathrm{H}_{2} \mathrm{O}_{2}\right)$, as depicted below [115]:

xanthine $+2 \mathrm{O}_{2}+\mathrm{H}_{2} \mathrm{O} \rightarrow$ uric acid $+2 \mathrm{O}_{2}^{-}+2 \mathrm{H}^{+}$

xanthine $+\mathrm{O}_{2}+\mathrm{H}_{2} \mathrm{O} \rightarrow$ uric acid $+\mathrm{H}_{2} \mathrm{O}_{2}$

The di-OH substitution at positions 5 and 7 , along with the presence of a double bond between C-2 and C-3 (requirements present in flavones such as apigenin and luteolin, and flavonols such as kaempferol and quercetin) are essential for the high XO inhibition activity [120]. These data are in accordance with a study that shows that the glycosylation of flavonoids can affect their XO inhibition activity [42].

Apigenin, quercetin, myricetin, isovitexins, and genistein are competitive inhibitors of XO. Apigenin has shown the most efficient inhibition, with the most favorable flavonoid active site of the enzyme interaction, and flavonoids with lower inhibitory activity were those that had higher glycoside residues such as isovitexin [121].

The acylation of flavonoids has significantly enhanced their XO inhibitory potential. The effect of the acyl donor chain length on the XO inhibition activity of isoquercitrin esters was evaluated and results indicated that all monoacylated derivatives of isoquercitrin (butyrate, caproate, caprylate, decanoate, laurate, palmitate, stearate, and oleate) showed higher $\mathrm{XO}$ inhibition activity than isoquercitrin. There was an increase in the $\mathrm{IC}_{50}$ values of saturated esters with the decrease in the carbon chain length (from 61 to $144 \mu \mathrm{M}$ for isoquercitrin stearate and butyrate, respectively) [38].

Higher inhibition activities were reported for isoquercitrin oleate (C18:1), which presents an unsaturation in the acyl group when compared to its saturated analogue $\left(\mathrm{IC}_{50}\right.$ values of $27 \mu \mathrm{M}$ and $61 \mu \mathrm{M}$, respectively). Also, the enzymatic acylation of isorhamnetin-3-O-glucoside with ethyl laurate and ethyl butyrate enhanced its capacity to inhibit XO and its antiproliferative activity, but decreased its radical scavenging activity [42].

One study found a linear relationship between the $\log \mathrm{IC}_{50}$ of mesquitol esters and their acyl chain length. The aliphatic 3-O acyl esters showed a better inhibition pattern. By elongating the alkyl chain in the acyl group, a better affinity was favored for the space around the active site of XO. This fact may be attributed to the increase of the lipophilicity of the molecule, which gives better accessibility to the active site of the enzyme [122]. Similarly, another study shows that the XO inhibition activity of flavonoids may be due to their surface activity properties, mainly their amphiphilic character [123]. Flavonoids with many hydroxyl groups, such as myricetin and quercetin, are almost insoluble in water, indicating that they can be surfactants because of the concomitant presence of hydrophilicity and hydrophobicity in each molecule [123]. 
Serine proteases (SP) belong to the most studied class of proteolytic enzymes, and are thus a primary target for drug discovery [124]. SP enzymes of interest include trypsin-like enzymes, such as trypsin, kallikrein, plasmin, thrombin and tryptase; chymotrypsin-like enzymes, including chymotrypsin, cathepsin G and chymase; elastase-like enzymes, including neutrophil elastase and elastase; and carboxypeptidase-like enzymes [125]. These enzymes are involved in a diverse array of biological functions such as cardiovascular function, blood pressure regulation, hormone processing, angiogenesis, digestion, immune response, bone remodeling, and ovulation.

The selective modification of polyphenols via lipophilization with fatty acids may represent a new approach to the production of potent, low toxicity SP inhibitors [126]. Potent protease inhibition was displayed by rutin and rutin derivatives esterified with medium- and long-chain, mono- and polyunsaturated fatty acids, followed by phloridzin and esculin derivatives with medium and long fatty acid chain lengths, while unmodified compounds showed little or no effect. A quantitative structure-activity relationship (QSAR) study of the compounds provided parameters for their inhibition activities, which are the number of hydrogen bond donors for urokinase, the molecular volume for thrombin, and the solvation energy for elastase. The statistical analysis showed that the action of elastase inhibitors is opposed to the action of urokinase and thrombin inhibitors [126].

Increased $5 \alpha$-reductase inhibition was observed after acylation of (-)-epigallocatechins. The activity of 3-acylated (-)-epigallocatechins increased with the increasing carbon numbers of the fatty acid moiety, reaching a maximum for 16 carbon atoms (compound $4 \mathrm{~h}$ ) with an $\mathrm{IC}_{50}$ of $0.53 \mu \mathrm{M}$, which was $\sim 12$-fold more potent than EGCG $\left(I_{50}=6.29 \mu \mathrm{M}\right)$. The introduction of monounsaturated fatty acid provided the most potent compound $\left(\mathrm{IC}_{50}=0.48 \mu \mathrm{M}\right)$, which showed moderate antitumor activity in vivo [127].

Quercetin, kaempferol, and morin act as competitive inhibitors of tyrosinase, and rhamnetin acts as a cofactor or substrate of tyrosines [128]. Tyrosinase is involved in the treatment of dermatological disorders such as hyperpigmentation, melanoma, and other skin disorders [129]. Two series of acylated derivatives of phloridzin and isoquercitrin with six long-chain saturated and mono- and poly-unsaturated fatty acids were synthesized, using L-3,4-dihydroxyphenylalanine (L-DOPA) as the binding enzyme substrate. The optimization of the reaction led to acylation rates from 81 to $98 \%$ in acetone, at $45^{\circ} \mathrm{C}$, using CALB. The $\alpha$-linolenic acid ester of isoquercitrin and docosahexaenoic acid ester of phloridzin showed the greatest tyrosinase inhibition potential. It was followed by linoleic acid, stearic acid, and oleic acid esters of isoquercitrin, respectively. The authors concluded that the presence of double bonds is crucial for inhibition but the increase in chain length, after a certain limit, prohibits the molecule from entering the enzyme core [48].

Among a series of nitrogen flavonoid derivatives, most showed a significant inhibitory effect on acetylcholine esterase activity. The most effective was the derivative containing pyrrolidine, which was more active than the commercial medicine Dopenezil [130].
Some investigations indicate that lipophilic flavonoid derivatives are strong inhibitors of transporting enzymes such as sarcoplasmic reticulum Ca2+-ATPase and plasma membrane Ca2+-ATPase $[19,131]$. The effect of lipophilic rutin derivatives (acylated with fatty acid chain length of 16-22) on sarco/endoplasmic reticulum $\mathrm{Ca}^{2+}$-ATPase (SERCA1 isoform) was evaluated and compared to the parent molecule rutin. Rutin derivatives caused a concentration-dependent decrease of SERCA1 activity $\left(\mathrm{IC}_{50} \sim 23-\right.$ $64 \mu \mathrm{M})$ and significant conformational alterations in the transmembrane region of the enzyme. The posttranslational modifications of SERCA1 by rutin esters include a significant loss of free sufhydryl groups, the protection of the enzyme from protein carbonyl formation, and the prevention of SERCA from tyrosinase (except R20:4 and R22:1). The inhibitory activity of the rutin esters is probably due to the interaction of these compounds with Glu771, a residue involved in $\mathrm{Ca}^{2+}$ binding [132].

Flavonoid acylated derivatives are inhibitors of enzymes from the renin-angiotensin-aldosterone system. Isoquercitrin and phloridzin were acylated with long-chain fatty acids (C18-C22) and tested for their in vitro inhibition of the angiotensin-converting enzyme, renin, and aldosterone synthase. Linoleic and linolenic acid derivatives of phloridzin were the strongest renin inhibitors ( IC $_{50}$ 69.9-70.9 $\left.\mu \mathrm{M}\right)$. Eicosapentaenoic acid derivatives of phloridzin were the strongest inhibitor of the angiotensin-converting enzyme ( $\left.\mathrm{IC}_{50} 16.0 \mu \mathrm{M}\right)$. However, all compounds had low or no effect on aldosterone synthase inhibition [133].

\section{Conclusion}

Enzymatic acylation of flavonoids is often an effective tool for structural and functional modification of these molecules for nutritional, pharmaceutical, and cosmetic applications. Lipase B from $C$. antarctica (CALB) is the most widely employed biocatalyst in these reactions, mainly due to its selectivity and high acylation rates. Several factors, such as the composition and water content of the reaction medium, the nature and chain length of the acyl donor, the acyl donor/flavonoid molar ratio, and temperature, may affect the lipase-catalyzed acylation of flavonoids. Choosing the best reaction conditions may improve the acylation rates. By increasing the lipophilicity of flavonoids, the use of these molecules in lipophilic systems may become more viable, and it may also increase their affinity with the cell membrane. Also, the enzymatic acylation of flavonoids has been described as an effective tool for the improvement of the biological activities of these compounds. Some of these effects are widely described in the literature, such as the antioxidant activity in vitro, the antiproliferative activity, and the enzyme inhibition activity. Thus, enzymatic acylation is a tool of interest for the research and application of these compounds as potential therapeutic adjuvants for the treatment of diseases related to damage caused by free radicals in the organism, as anti-inflammatories, and as chemotherapeutic adjuvants in cancer therapy. However, further investigation of the activity of acylated flavonoids in vivo is necessary to elucidate the mechanisms of action and the efficacy of these compounds further. 


\section{Acknowledgements}

We acknowledge CAPES (Coordination for the Improvement of Higher Education Personnel) for the postgraduate scholarships.

\section{Conflict of Interest}

The authors declare no conflict of interest.

\section{References}

[1] Kumar S, Pandey AK. Chemistry and biological activities of flavonoids: an overview. ScientificWorldjournal 2013; 2013: 162750

[2] Danihelová M, Veverka M, Šturdík E, Jantová S. Antioxidant action and cytotoxicity on HeLa and NIH-3T3 cells of new quercetin derivatives. Interdiscip Toxicol 2013; 6: 209-216

[3] Zhao W, Sun J, Xiang H, Zeng YY, Li XB, Xiao H, Chen DY, Ma RL. Synthesis and biological evaluation of new flavonoid fatty acid esters with antiadipogenic and enhancing glucose consumption activities. Bioorg Med Chem 2011; 19: 3192-3203

[4] Fukami H, Nakao M, Namikawa K, Maeda M. Esterified catechin, process for producing the same, food and drink or cosmetic containing the same. EP Patent 1849779; 2007

[5] Gao C, Mayon P, Macmanus DA, Vulfson EN. Novel enzymatic approach to the synthesis of flavonoid glycosides and their esters. Biotechnol Bioeng 2000; 71: 235-243

[6] Katsoura MH, Polydera AC, Tsironis L, Tselepis AD, Stamatis H. Use of ionic liquids as media for the biocatalytic preparation of flavonoid derivatives with antioxidant potency. J Biotechnol 2006; 123: 491-503

[7] Mellou F, Loutrari H, Stamatis H, Roussos C, Kolisis FN. Enzymatic esterification of flavonoids with unsaturated fatty acids: effect of the novel esters on vascular endothelial growth factor release from K562 cells. Process Biochem 2006; 41: 2029-2034

[8] Mellou F, Lazari D, Skaltsa H, Tselepis A, Kolisis F, Stamatis H. Biocatalytic preparation of acylated derivatives of flavonoid glycosides enhances their antioxidant and antimicrobial activity. J Biotechnol 2005; 116: 295-304

[9] Ardhaoui M, Falcimaigne A, Ognier S, Engasser JM, Moussou P, Pauly G, Ghoul M. Effect of acyl donor chain length and substitutions pattern on the enzymatic acylation of flavonoids. J Biotechnol 2004; 110: 265-271

[10] Ardhaoui M, Falcimaigne A, Engasser JM, Moussou P, Pauly G, Ghoul M. Acylation of flavonoids using lipase of Candida antarctica as biocatalyst. J Mol Catal B Enzym 2004; 29: 63-67

[11] Ardhaoui M, Falcimaigne A, Engasser JM, Moussou P, Ghoul M. Enzymatic synthesis of new aromatic and aliphatic esters of flavonoids using Candida antarctica lipase as biocatalyst. Biocatal Biotransformation 2004; 22 : 253-259

[12] Enaud E, Humeau C, Piffaut B, Girardin M. Enzymatic synthesis of new aromatic esters of phloridzin. J Mol Catal B Enzym 2004; 27: 1-6

[13] Gayot S, Santarelli X, Coulon D. Modification of flavonoid using lipase in nonconventional media: effect of the water content. J Biotechnol 2003; 101: 29-36

[14] Kontogianni A, Skouridou V, Serteti V, Stamatis H, Kolisis FN. Lipase-catalyzed esterification of rutin and naringin with fatty acids of medium carbon chain. J Mol Catal B Enzym 2003; 21: 59-62

[15] Haddad AQ, Venkateswaran V, Viswanathan L, Teahan SJ, Fleshner NE, Klotz LH. Novel antiproliferative flavonoids induce cell cycle arrest in human prostate cancer cell lines. Prostate Cancer Prostatic Dis 2006; 9: 68-76
[16] Clark J. Green chemistry: challenges and opportunities. Green Chem 1999; 1: 1-8

[17] Schmid A, Dordick ], Hauer B, Kiener A, Wubbolts M, Witholt B. Industria biocatalysis today and tomorrow. Nature 2001; 409: 258-268

[18] Chebil L, Humeau C, Falcimaigne A, Engasser JM, Ghoul M. Enzymatic acylation of flavonoids. Process Biochem 2006; 41: 2237-2251

[19] Viskupicova J, Ondrejovic M, Sturdik E. The potential and practical applications of acylated flavonoids. Pharmazie 2009; 64: 355-360

[20] Xanthakis E, Theodosiou E, Magkouta S, Stamatis H, Loutrari H, Roussos C, Kolisis F. Enzymatic transformation of flavonoids and terpenoids: structural and functional diversity of the novel derivatives. Pure Appl Chem 2010; 82: 1-16

[21] Tarahovsky YS, Kim YA, Yagolnik EA, Muzafarov EN. Flavonoid-membrane interactions: involvement of flavonoid-metal complexes in raft signaling. Biochim Biophys Acta 2014; 1838: 1235-1246

[22] Van Dijk C, Driessen A], Recourt K. The uncoupling efficiency and affinity of flavonoids for vesicles. Biochem Pharmacol 2000; 60: 1593-1600

[23] Kyriakou E, Primikyri A, Charisiadis P, Katsoura M, Gerothanassis IP, Stamatis H, Tzakos AG. Unexpected enzyme-catalyzed regioselective acylation of flavonoid aglycones and rapid product screening. Org Biomol Chem 2012: 10: 1739-1742

[24] Collins AM, Kennedy M]. Biotransformations and bioconversions in New Zealand: past endeavours and future potential. Australas Biotechnol 1999; 9: 86-94

[25] Nagasawa T, Yamada H. Microbial production of commodity chemicals. Pure Appl Chem 1995; 67: 1241-1256

[26] Rajendram A, Palanisamy A, Thangavelu V. Lipase catalyzed ester synthesis for food processing industries. Braz Arch Biol Technol 2009; 52 207-219

[27] Ferreira-Dias S, Sandoval G, Plou F, Valero F. The potential use of lipases in the production of fatty acid derivatives for the food and nutraceutical industries. Electron J Biotechn 2013; 16: 1

[28] Degn P, Pedersen LH, Duus J, Zimmerman W. Lipase-catalysed synthesis of glucose fatty acid esters in tert-butanol. Biotechnol Lett 1999; 21: 275-280

[29] Anderson EM, Larsson KM, Kirk O. One biocatalyst - many applications: the use of Candida Antarctica B lipase in organic synthesis. Biocatal Biotransformation 1998; 6: 181-204

[30] Cordova A, Iversen T, Hult K, Martinelle M. Lipase-catalysed formation of macrocycles by ring-opening polymerisation of $\varepsilon$-caprolactone. Polymer (Guildf) 1998; 39: 6519-6524

[31] Lutz S. Engineering lipase B from Candida antarctica. Tetrahedron Asymmetry 2004; 15: 2743-2748

[32] Araújo ME, Contesini F], Franco YEM, Sawaya ACF, Alberto TG, Dalfré N, Carvalho PO. Optimized enzymatic synthesis of hesperidin fatty acid esters in a two-phase system containing ionic liquid. Molecules 2011; 16: 7171-7182

[33] De Oliveira EB, Humeau C, Chebil L, Maia ER, Dehez F, Maigret B, Ghou M, Engasser JM. A molecular modelling study to rationalize the regioselectivity in acylation of flavonoid glycosides catalyzed by Candida antarctica lipase B. J Mol Catal B Enzym 2009; 59: 96-105

[34] Razak NNA, Annuar MSM. Enzymatic synthesis of flavonoid ester: Elucidation of its kinetic mechanism and equilibrium thermodynamic behavior. Ind Eng Chem Res 2015; 54: 5604-5612

[35] Trodler P, Pleiss J. Modeling structure and flexibility of Candida antarctica lipase B in organic solvents. BMC Struct Biol 2008; 8: 9

[36] Nakajima N, Ishihara K, Itoh T, Furuya T, Hamada H. Lipase catalysed direct and regioselective acylation of flavonoid glucoside for mechanistic investigation of stable plant pigments. J Biosci Bioeng 1999; 61: 19261928

[37] Danieli B, Luisetti M, Sampognaro G, Carrea G, Riva S. Regioselective acylation of polyhydroxylated natural compounds catalyzed by Candida 
antarctica lipase B (Novozym 435) in organic solvents. I Mol Catal B Enzym 1997; 3: 193-201

[38] Salem JH, Humeau C, Chevalot I, Harscoat-Schiavo C, Vanderesse R, Blanchard F, Fick M. Effect of acyl donor chain length on isoquercitrin acylation and biological activities of corresponding esters. Process Biochem 2010; 45: 382-389

[39] Viskupicova J, Danihelova M, Ondrejovic M, Liptaj T, Sturdik E. Lipophilic rutin derivatives for antioxidant protection of oil-based foods. Food Chem 2010; 123: 45-50

[40] Passicos E, Santarelli X, Coulon D. Regioselective acylation of flavonoids catalyzed by immobilized Candida antarctica lipase under reduced pressure. Biotechnol Lett 2004; 26: 1073-1076

[41] Theodosiou E, Loutrari H, Stamatis H, Roussos C, Kolisis FN. Biocatalytic synthesis and antitumor activities of novel silybin acylated derivatives with dicarboxylic acids. N Biotechnol 2011; 28: 342-348

[42] Salem JH, Chevalot I, Harscoat-Schiavo C, Paris C, Fick M, Humeau C. Biological activities of flavonoids from Nitraria retusa (Forssk.) Ach. and their acylated derivatives. Food Chem 2011; 124: 486-494

[43] Katsoura MH, Polydera AC, Katapodis P, Kolisis FN, Stamatis H. Effect of different reaction parameters on the lipase-catalyzed selective acylation of polyhydroxylated natural compounds in ionic liquids. Process Biochem 2007; 42: 1326-1334

[44] Céliz G, Daz M. Biocatalytic preparation of alkyl esters of citrus flavanone glucoside prunin in organic media. Process Biochem 2011; 46: 94-100

[45] Lue BM, Guo Z, Glasius M, Xu X. Scalable preparation of high purity rutin fatty acids esters. J Am Oil Chem Soc 2010; 87: 551-561

[46] Almeida VM, Branco CRC, Assis SA, Vieira IJC, Braz-Filho R, Branco A. Synthesis of naringin 6"-ricinoleate using immobilized lipase. Chem Cent J 2012; 6: 41-47

[47] Céliz G, Martearena MR, Scaroni E, Daz M. Kinetic study of the alkyl flavonoid ester prunin-6"-O-laurate synthesis in acetone catalysed by immobilised Candida antarctica lipase B. Biochem Eng J 2012; 69: 69-74

[48] Ziaullah KS, Bhullar SN, Warnakulasuriya HP, Rupasinghe V. Biocatalytic synthesis, structural elucidation, antioxidant capacity and tyrosinase inhibition activity of long chain fatty acid acylated derivatives of phloridzin and isoquercitrin. Bioorg Med Chem 2013; 21: 684-692

[49] Viskupicova J, Ondrejovic M, Maliar T. Enzyme-mediated preparation of flavonoid esters and their applications. Biochemistry 2012; 10: 263-278

[50] Danihelova M, Viskupicova ], Sturdik E. Lipophilization of flavonoids for their food, therapeutic and cosmetic applications. Acta Chim Slov 2012; 5: 59-69

[51] Welton T. Room-temperature ionic liquids. Solvents for synthesis and catalysis. Chem Rev 1999; 99: 2071-2083

[52] Park S, Kazlauskas RJ. Biocatalysis in ionic liquids - advantages beyond green technology. Curr Opin Biotechnol 2003; 14: 432-437

[53] Moon YH, Lee SM, Ha SH, Koo YM. Enzyme-catalyzed reactions in ionic liquids. Korean J Chem Eng 2006; 23: 247-263

[54] Van Rantwijk F, Sheldon RA. Biocatalysis in ionic liquids. Chem Rev 2007; 107: 2757-2785

[55] Park S, Kazlauskas RJ. Improved preparation and use of room temperature ionic liquids in lipase-catalyzed enantio- and regioselective acylations. J Org Chem 2001; 66: 8395-8401

[56] De Diego T, Lozano P, Gmouh S, Vaultier M, Iborra JL. Understanding structure-stability relationships of Candida antarctica lipase B in ionic liquids. Biomacromolecules 2005; 6: 1457-1464

[57] Lue BM, Nielsen NS, Jacobsen C, Hellgren L, Guo Z, Xu X. Antioxidant properties of modified rutin esters by DPPH, reducing power, iron chelation and human low density lipoprotein assays. Food Chem 2010; 123 : 221-230

[58] Arroyo M, Sánchez-Montero JM, Sinisterra JV. Thermal stabilization of immobilized lipase B from Candida antarctica on different supports: effect of water activity on enzymatic activity in organic media. Enzyme Microb Technol 1999; 24: 3-12

[59] Zaks A, Klibanov AM. Enzymatic catalysis in nonaqueous solvents. J Biol Chem 1988; 263: 3194-3201

[60] Stevenson DE, Wibisono R, Jensen DJ, Stanley RA, Cooney JM. Direct acylation of flavonoid glycosides with phenolic acids catalysed by Candida antarctica lipase B (Novozym 435). Enzyme Microb Technol 2006; 39: 1236-1241

[61] Pirozzi D, Greco FG jr. Activity and stability of lipases in the synthesis of butyl lactate. Enzyme Microb Technol 2004; 34: 94-100

[62] Zhao H. Effect of ions and other compatible solutes on enzyme activity, and its implication for biocatalysis using ionic liquids. J Mol Catal B Enzym 2005; 37: 16-25

[63] Jewur SS. Química de zeólitas e catálise. Quim Nova 1985; 8: 99-105

[64] Ballesteros A, Plou FJ, Alcade M, Ferrer M, Garcia-Arellano H, ReyesDuarte D, Ghazi I. Enzymatic Synthesis of Sugar Esters and Oligosaccharides from renewable Resources. In: Patel RN, ed. Biocatalysis in the pharmaceutical and Biotechnology Industries. Boca Raton: CRC Press; 2006; 463-488

[65] Pleiss J, Fischer M, Schmid RD. Anatomy of lipase binding sites: the scissile fatty acid binding site. Chem Phys Lipids 1998; 93: 67-80

[66] Viskupicova J, Ondrejovič M. Effect of fatty acid Chain Length on enzymatic Esterification of Rutin. In: Martin Pipíška, ed. Book of Abstracts of the 1st International Conference of Applied Natural Sciences. Trnava, Slovakia: UCM; 2007: 59

[67] Patti A, Piattelli M, Nicolosi G. Use of Mucor miehei lipase in the preparation of long chain 3-O-acylcatechins. J Mol Catal B Enzym 2000; 10: 577 582

[68] Solomons TWG, Fryhle CB. Organic Chemistry, 7th ed. New York: Wiley; 2001

[69] Kontogianni A, Skouridou V, Sereti V, Stamatis H, Kolisis FN. Regioselec tive acylation of flavonoids catalyzed by lipase in low toxicity media. Eur J Lipid Sci Tech 2001; 103: 655-660

[70] Ishihara K, Nakajima N. Structural aspects of acylated plant pigments: stabilization of flavonoid glucosides and interpretation of their functions. J Mol Catal B Enzym 2003; 23: 411-417

[71] Ghoul M, Engasser JM, Moussou P, Pauly G, Ardhaoui M, Falcimaigne A. Enzymatic production of acyl flavonoid derivatives. US Patent 20060115880 A $1 ; 2006$

[72] Viskupicova J, Maliar T, Psenakova I, Sturdik E. Enzymatic acylation of naringin. Nova Biotechnol 2006; 6: 149-159

[73] Kappe CO, Dallinger D. Controlled microwave heating in modern organic synthesis: highlights from the 2004-2008 literature. Mol Divers 2009; 13: 71

[74] Batistella L, Lerin LA, Brugnerotto P, Danielli A], Trentin CM, Popiolski A, Treichel H, Oliveira JV, De Oliveira D. Ultrasound-assisted lipase-catalyzed transesterification of soybean oil in organic solvent system. Ultrason Sonochem 2012; 19: 452-458

[75] Ziaullah, Rupasinghe HP. An efficient microwave-assisted enzyme-catalyzed regioselective synthesis of long chain acylated derivatives of flavonoid glycosides. Tetrahedron Lett 2013; 54: 1933-1937

[76] La Cara F, d'Auria S, Scarfi MR, Zeni O, Massa R, d'Ambrioso G, Franceschetti G, De Rosa M, Rossi M. Microwave exposure effect on a thermophilic alcohol desidrogenase. Protein Pept Lett 1999; 6: 155-162

[77] Mazumder S, Laskar DD, Prajapati D, Roy MK. Microwave-induced enzyme-catalyzed chemoselective reduction of organic azides. Chem Biodivers 2004; 1: 925-929

[78] Hobuss CB, Venzke D, Pacheco BS, Souza AO, Santos MAZ, Moura S, Quina FH, Fiametti KG, Oliveira JV, Pereira CMP. Ultrasound-assisted synthesis of aliphatic acid esters at room temperature. Ultrason Sonochem 2012; 19: 387-389 
[79] Zengh MM, Wang L, Huang FH, Dong L, Guo PM, Deng QC, Li WL, Zheng C. Ultrasonic pretreatment for lipase-catalyed synthesis of phytosterol esters with different acyl donors. Ultrason Sonochem 2012; 19: 10151020

[80] Ziaullah, Rupasinghe HP. Sonochemical enzyme-catalyzed regioselective acylation of flavonoid glycosides. Bioorg Chem 2016; 65: 17-25

[81] Medina I, Alcantara D, Gonzalez M], Torres P, Lucas R, Roque J, Plou F], Morales JC. Antioxidant activity of resveratrol in several fish lipid matrices: effect of acylation and glucosylation. J Agric Food Chem 2010; 58: 9778-9786

[82] Shahidi F. Nutraceutical, functional foods and dietary supplements in health and disease. J Food Drug Anal 2012; 20: 226-230

[83] Warnakulasuriya SN, Ziaullah, Rupasinghe HPV. Long chain fatty acid acylated derivatives of quercetin-3-0-glucoside as antioxidants to prevent lipid oxidation. Biomolecules 2014; 4: 980-993

[84] Ma X, Yan R, Yu S, Lu Y, Li Z, Lu H. Enzymatic acylation of isoorientin and isovitexin from bamboo-leaf extracts with fatty acids and antiradical activity of the acylated derivatives. J Agric Food Chem 2012; 60: 10844-10849

[85] Xu J, Qian J, Li S. Enzymatic acylation of isoorientin isolated from antioxidant of bamboo leaves with palmitic acid and antiradical activity of the acylated derivatives. Eur Food Res Technol 2014; 239: 661-667

[86] Milisavljević A, Stojanović M, Carević M, Mihailović M, Veličković D, Milosavić N, Bezbradica D. Lipase-catalyzed esterification of phloridzin: Acyl donor effect on enzymatic affinity and antioxidant properties of esters. Ind Eng Chem Res 2014; 53: 16644-16651

[87] Zhu S, Li Y, Li Z, Ma C, Lou Z, Yokoyama W, Wang H. Lipase-catalyzed synthesis of acetylated EGCG and antioxidant properties of the derivatives. Food Res Int 2014; 56: 279-286

[88] Karabin M, Hudcova T, Jelinek L, Dostalek P. Biotransformations and biological activities of hop flavonoids. Biotechnol Adv 2015; 33: 1063-1090

[89] Ravishankar D, Rajora AK, Greco F, Osborn HMI. Flavonoids as prospective compounds for anti-cancer therapy. Int J Biochem Cell Biol 2013; 45: 2821-2831

[90] Liu HL, Jiang WB, Xie MX. Flavonoids: recent advances as anticancer drugs. Recent Pat Anticancer Drug Discov 2010; 5: 152-164

[91] Nair SVG, Ziaullah, Rupasinghe HPV. Fatty acid esters of phloridzin induce apoptosis of human liver cancer cells through altered gene expression. PLoS One 2014; 9: e107149

[92] Sudan S, Rupasinghe HPV. Antiproliferative activity of long chain acylated esters of quercetin-3-O-glucoside in hepatocellular carcinoma HepG2 cells. Exp Biol Med 2015; 240: 1452-1464

[93] Warnakulasuriya SN, Ziaullah, Rupasinghe HPV. Novel long chain fatty acid derivatives of quercetin-3-O-glucoside reduce cytotoxicity induced by cigarette smoke toxicants in human fetal lung fibroblasts. Eur J Pharmacol 2016; 781: 128-138

[94] Warnakulasuryia SN, Ziaullah, Rupasinghe HP. Long chain fatty acid esters of quercetin-O-glucoside attenuate $\mathrm{H}_{2} \mathrm{O}_{2}$-induced acute cytotoxicity in human lung fibroblasts and primary hepatocytes. Molecules 2016; 21: 452

[95] Rathee P, Chaudhary H, Rathee S, Rathee D, Kumar V, Kohli K. Mechanism of action of flavonoids as anti-inflammatory agents: a review. Inflamm Allergy Drug Targets 2009; 8: 229-235

[96] Hoang TK, Huynh TK, Nguyen T. Synthesis, characterization, anti-inflammatory and anti-proliferative activity against MCF-7 cells of O-alkyl and O-acyl flavonoid derivatives. Bioorg Chem 2015; 63: 45-52

[97] Liu LY, Jin C, Zhang Y. Lipophilic phenolic compounds (Lipo-PCS): emerging antioxidants applied in lipid systems. RSC Adv 2014; 6: 2879-2891

[98] Tubaro A, Del Negro P, Bianchi P, Romussi G, Della Loggia R. Topical antiinflammatory activity of a new acylated flavonoid. Agents Actions 1989; 26: $1-2$
[99] Shen Y, Zhang J, Sheng R, Dong X, He Q, Yang B, Hu Y. Synthesis and biological evaluation of novel flavonoid derivatives as dual binding acetylcholinesterase inhibitors. J Enzyme Inhib Med Chem 2009; 24: 372380

[100] Li RS, Wang XB, Xu X], Kong LY. Design, synthesis and evaluation of flavonoid derivatives as potential multifunctional acetylcholinesterase inhibitors against Alzheimer's disease. Bioorg Med Chem Lett 2013; 23: $2636-2641$

[101] Harborne JB, Williams CA. Advances in flavonoid research since 1992. Phytochemistry 2000; 55: 481-504

[102] Mossou P, Falcimaigne A, Ghoul M, Danoux L, Pauly G. Esters of flavonoids with w-substituted C6-C22 fatty acids. US Patent 20070184098; 2007

[103] Lee S], Baek H], Lee CH, Kim HP. Antiinflammatory activity of isoflavonoids from Pueraria radix and biochanin A derivatives. Arch Pharm Res 1994; 17: 31-35

[104] Park KD, Park YS, Cho SJ, Sun WS, Kim SH, Jung DH. Antimicrobial activity of 3-O-acyl-(-)-epicatechin and 3-O-acyl-(+)- catechin derivatives. Planta Med 2004; 70: 272-276

[105] Amen HY, Marzouka AM, Zaghloula MG, Afifia MS. A new acylated flavonoid tetraglycoside with anti-inflammatory activity from Tipuana tipu leaves. Nat Prod Res 2015; 29: 511-517

[106] Albert A, Courbat P, Weith A. Process for the preparation of O-substituted derivatives of (+)-cyanidan-3-01. US Patent 4255336; 1981

[107] Sekhon-Loodu S, Ziaullah Z, Rupasinghe HPV, Wang Y, Kulka M, Shahidi F. Novel quercetin-3-O-glucoside eicosapentaenoic acid ester ameliorates inflammation and hyperlipidemia. Inflammopharmacology 2015; $23: 173-185$

[108] Sekhon-Loodu S, Ziaullah, Rupasinghe HP. Docosahexaenoic acid ester of phloridzin inhibits lipopolysaccharide-induced inflammation in THP-1 differentiated macrophages. Int Immunopharmacol 2015; 1: 199-206

[109] Rauha JP, Remes S, Heinonen M, Hopia A, Kähkönen M, Kujala T, Pihlaja $\mathrm{K}$, Vuorela H, Vuorela P. Antimicrobial effects of Finnish plant extracts containing flavonoids and other phenolic compounds. Int J Food Microbiol 2000; 56: 3-12

[110] Aziz NH, Farag SE, Mousa LA, Abo-Zaid MA. Comparative antibacterial and antifungal effects of some phenolic compounds. Microbios 1998; 93: 43-54

[111] Stapleton PD, Shah S, Hamilton-Miller JMT, Hara Y, Nagaoka Y, Kumagai A, Uesato S, Taylor PW. Anti-Staphylococcus aureus activity and oxacillin resistance modulating capacity of 3-O-acyl-catechins. Int ] Antimicrob Agents 2004; 24: 374-380

[112] Kodelia G, Athanasiou K, Kolisis FN. Enzymatic synthesis of butyrylrutin ester in organic solvents and its cytogenetic effects in mammalian cells in culture. Appl Biochem Biotechnol 1994; 44: 205-212

[113] Park KD, Cho SJ. Synthesis and antimicrobial activities of 3-O-alkyl analogues of ( $($ )-catechin: improvement of stability and proposed action mechanism. Eur J Med Chem 2010; 45: 1028-1033

[114] Grippa E, Valla R, Battinelli L, Mazzanti G, Saso L, Silvestrini B. Inhibition of Candida rugosa lipase by berberine and structurally related alkaloids, evaluated by high-performance liquid chromatography. Biosci Biotechnol Biochem 1999; 63: 1557-1562

[115] Gatto MT, Falcocchio S, Grippa E, Mazzanti G, Battinelli L, Nicolosi G, Lambustab D, Saso L. Antimicrobial and anti-lipase activity of quercetin and its C2-C16 3-O-acyl-esters. Bioorg Med Chem 2002; 10: 269-272

[116] Salas MP, Céliz G, Geronazzo H, Daz M, Resnik SL. Antifungal activity of natural and enzymatically-modified flavonoids isolated from citrus species. Food Chem 2011; 124: 1411-1415

[117] Muzna S, Divya D, Kamat SD, Kamat D. Antifungal activity of lipase modified flavonoids from citrus limetta. Int J Pharm Pharm Sci 2014; 6: $116-118$ 
[118] Harmalkar A, Shaikh M, Kamat S, Kamat D. Enzyme assisted transformation of glycosides. South As J Biol Sci 2013; 3: 40-45

[119] Hanasaki Y, Ogawa S, Fukui S. The correlation between active oxygen scavenging and antioxidative effects of flavonoids. Free Radic Biol Med 1994; 16: 845-850

[120] Cos P, Ying L, Calomme M, Hu JP, Cimanga K, Van Poel B. Structureactivity relationship and classification of flavonoids as inhibitors of xanthine oxidase and superoxide scavengers. J Nat Prod 1998; 61: 71-76

[121] Lin CM, Chen CS, Chen CT, Liang YC, Lin JK. Molecular modeling of flavonoids that inhibits xanthine oxidase. Biochem Biophys Res Commun 2002; 294: 167-172

[122] Rao RJ, Tiwari A, Kumar US, Reddy SV, Ali S, Rao JM. Novel 3-O-acyl mesquitol analogues as free-radical scavengers and enzyme inhibitors: synthesis, biological evaluation and structure-activity relationship. Bioorg Med Chem Lett 2003; 13: 2777-2780

[123] Lio M, Moriyama A, Matsumoto Y, Takaki N, Fukumoto M. Inhibition of xanthine oxidase by flavonoids. Agric Biol Chem 1985; 49: 2173-2176

[124] Fear G, Komarnytsky S, Raskin I. Protease inhibitors and their peptidomimetic derivatives as potential drugs. Pharmacol Ther 2007; 113: 354-368

[125] Clark JM, Jenkins TE, Katz BA, Stroud RM. Metal complexed serine protease inhibitors. US Patent 5693515A; 1997

[126] Viskupicova J, Danihelova M, Majekova M, Liptaj T, Sturdik E. Polyphenol fatty acid esters as serine protease inhibitors: a quantum-chemical QSAR analysis. J Enzyme Inhib Med Chem 2012; 27: 800-809
[127] Lin SF, Lin YH, Lin M, Kao YF, Wang RW, Teng LW, Chuang SH, Chang JM, Yuan TT, Fu KC, Huang KP, Lee YS, Chiang CC, Yang SC, Lai CL, Liao CB, Chen P, Lin YS, Lai KT, Huang HJ, Yang JY, Liu CW, Wei WY, Chen CK, Hiipakka RA, Liao S, Huang JJ. Synthesis and structure-activity relationship of 3-O-acylated (e)-epigallocatechins as $5 \alpha$-reductase inhibitors. Eur J Med Chem 2010; 45: 6068-6076

[128] Kim YJ, Uyama H. Tyrosinase inhibitors from natural and synthetic sources: structure, inhibition mechanism and perspective for the future. Cell Mol Life Sci 2005; 62: 1707-1723

[129] Khan MT. Novel tyrosinase inhibitors from natural resources - their computational studies. Curr Med Chem 2012; 19: 2262-2272

[130] Sheng R, Lin X, Zhang J, Chol KS, Huang W, Yang B, He Q, Hu Y. Design, synthesis and evaluation of flavonoid derivatives as potent $A C h E$ inhibitors. Bioorg Med Chem 2009; 17: 6692-6698

[131] Augustyniak A, Bartosz G, Cipak A, Duburs G, Horakova L, Luczaj W, Majekova M, Odysseos AD, Rackova L, Skrzydlewska E, Stefek M, Strosova M, Tirzitis G, Viskupicova J, Vraka PS, Zarkovic N. Natural and synthetic antioxidants: an updated overview. Free Radic Res 2010; 44: 1216-1262

[132] Viskupicova J, Majekova M, Horakova L. Inhibition of the sarco/endoplasmic reticulum Ca2+-ATPase (SERCA1) by rutin derivatives. Juscle Res Cell Motil 2015; 36: 183-194

[133] Bhullar KS, Ziaullah, Rupasinghe HPV. In vitro regulation of enzymes of the renin-angiotensin-aldosterone system by isoquercitrin, phloridzin and their long chain fatty acid derivatives. Funct Food Health Dis 2014; 4: 208-221 